\title{
Wtip is required for proepicardial organ specification and cardiac left/right asymmetry in zebrafish
}

\author{
REBECCA POWELL $^{1 *}$, EKATERINA BUBENSHCHIKOVA ${ }^{1 *}$, YAYOI FUKUYO $^{1 *}$, CHAONAN HSU $^{1}$, \\ OLGA LAKIZA $^{1}$, HIROKI NOMURA ${ }^{1}$, ERIN RENFREW ${ }^{2}$, DEBORAH GARRITY $^{2}$ and TOMOKO OBARA ${ }^{1}$ \\ ${ }^{1}$ Department of Cell Biology, University of Oklahoma Health Sciences Center, Oklahoma, OK 73104; \\ ${ }^{2}$ Department of Biology, Colorado State University, Fort Collins, CO 80523, USA
}

Received January 1, 2016; Accepted June 2, 2016

DOI: $10.3892 / \mathrm{mmr} .2016 .5550$

\begin{abstract}
Wilm's tumor 1 interacting protein (Wtip) was identified as an interacting partner of Wilm's tumor protein (WT1) in a yeast two-hybrid screen. WT1 is expressed in the proepicardial organ (PE) of the heart, and mouse and zebrafish wtl knockout models appear to lack the PE. Wtip's role in the heart remains unexplored. In the present study, we demonstrate that wtip expression is identical in wtla-, tcf 21 -, and tbx18-positive PE cells, and that Wtip protein localizes to the basal body of PE cells. We present the first genetic evidence that Wtip signaling in conjunction with WT1 is essential for PE specification in the zebrafish heart. By overexpressing wtip mRNA, we observed ectopic expression of PE markers in the cardiac and pharyngeal arch regions. Furthermore, wtip knockdown embryos showed perturbed cardiac looping and lacked the atrioventricular (AV) boundary. However, the chamber-specific markers $a m h c$ and $v m h c$ were unaffected. Interestingly, knockdown of wtip disrupts early left-right (LR) asymmetry. Our studies uncover new roles for Wtip regulating PE cell specification and early LR asymmetry, and suggest that the PE may exert non-autonomous effects on heart looping and AV morphogenesis. The presence of cilia in the PE, and localization of Wtip in the basal body of ciliated cells, raises the possibility of cilia-mediated PE signaling in the embryonic heart.
\end{abstract}

\section{Introduction}

The heart is one of the first organs to form during development from the lateral plate mesoderm (1-3). The primitive

Correspondence to: Professor Tomoko Obara, Department of Cell Biology, University of Oklahoma Health Sciences Center, 940 Stanton L. Young Blvd., BMSB782, Oklahoma, OK 73104, USA E-mail: tomoko-obara@ouhsc.edu

*Contributed equally

Key words: WT1, wtip, tcf21, proepicardial organ, cilia, heart looping, atrioventricular boundary, left-right asymmetry, zebrafish heart tube consists of two layers: The endocardium and the myocardium (4). Progenitor cells in the lateral plate mesoderm migrate toward the midline, where they form the two-layered heart tube. Subsequent morphological changes are necessary to shape this primitive heart tube into the chambered heart organ and for the atrioventricular (AV) boundary to develop between chambers that provide directional flow. In addition to the endocardium and myocardium, a third cellular layer, the epicardium, develops from an extracardiac population of cells called the proepicardial organ (PE) (5-12).

The mesodermally-derived epicardium covers the myocardial layer and is known to provide signaling required for proper development of the heart (13-15). However, the molecular regulation of epicardial function is just beginning to be investigated. Wilm's tumor protein (wt1), vascular cell adhesion protein 1 and $\alpha 4$ integrin genes are essential for epicardium formation. Targeted mutagenesis of these genes in mice provided genetic evidence supporting a role in cardiac development (16-19). Additional evidence suggested that the PE contributes to the development of the coronary vessels, and is required for continued cardiac development and function $(5-11,20,21)$.

Previous studies indicated that in zebrafish, similar to other vertebrates, the PE can be distinguished morphologically at $48 \mathrm{~h}$ post fertilization (hpf) as a group of cells located in close proximity to the ventral wall of the heart $(22,23)$. The PE is characterized by the expression of wtla, transcription factor 21 (tcf21), and T box 18 (tbx18) at 48 hpf $(22,23)$. Specification of the PE requires a bone morphogenic protein (BMP) ligand, which is not, as previously assumed, derived from the liver bud (23). Instead, cardiac-specific bmp 4 signaling from the myocardium induces PE specification. Independent from Bmp4 signaling, tbx5 expression in the lateral mesoderm during the early somite stages is also required for PE specification (23). Previous studies in adult zebrafish hearts indicate that the epicardium forms a smooth surface covering the entire heart wall. Additionally, it was discovered that partial amputation of the adult heart elevated the expression of tbx18 and retinaldehyde dehydrogenase 2, which suggests that epicardial genes serve a critical role in the response to injury (24-26). The activated epicardial cells proliferate and undergo epithelial-to-mesenchymal transition, which requires platelet-derived growth factor (27) and $\beta$-catenin and retinoic 
acid signaling (21). The developmentally activated epicardial cells quickly invade the proliferating myocardium at the site of injury and create a dense vascular network that is likely to encourage regeneration (24-27).

In addition to its role in response to heart injury, the epicardium has important regulatory functions in the normal development of the myocardium (17,18,28-31). Despite the central role of epicardial signaling during heart development and repair, the molecular signals driving specification of the PE remain poorly understood.

In chicks, the PE first forms in a bilaterally symmetrical fashion, and then develops asymmetrically. Disruption of genes required for specifying right-sidedness in the body, such as fibroblast growth factor 8 (fgf8) or snail homolog 1 (snaill), prevented PE specification (32). In mice, the dependence of PE specification on the left-right (LR) body axis is unclear. In this organism, both PE precursors develop equally on both sides, and later fuse at the midline to generate the PE (33). Establishment of the LR axis in the zebrafish heart depends on global LR cues that are generated by cilia during early gastrulation stages (34). Abnormal LR development can affect cardiac looping during vertebrate morphogenesis. Therefore, some cardiac defects that are associated with the abnormal positioning of the cardiac chambers or with vessel malformation are secondary to altered LR development (35). However, some patients demonstrate heterotaxy of the heart without other obvious LR defects, suggesting that ciliary function may also have an important role in cardiovascular morphogenesis itself (36-38). Slough et al (39) reported the presence of monocilia in several areas of the mouse embryonic heart, suggesting a role for cilia in cardiac morphogenesis. Furthermore, hearts in kinesin-3a (Kif3a) mutants developed abnormal endocardial cushions (ECCs) and thinner compact myocardium, and completely lacked cardiac cilia (39). Additionally, the compact myocardium was thinner in embryos mutant for polycystic kidney disease 2, a protein that functions as a mechanosensor in the kidney and node (39).

The WT1-interacting protein (Wtip) was originally identified as an interacting partner of WT-1 in a yeast two-hybrid screen (40). Recent studies and previous work by our group revealed the following roles for Wtip: i) Wtip interacts with the C-terminus of receptor tyrosine kinase-like orphan receptor 2 in yeast and mammalian cells (41); ii) Ajuba LIM proteins [Ajuba, LIM domain containing 1 (LIMD1), and Wtip] interact with Snail to remodel epithelial dynamics $(42,43)$; iii) Wtip is a LIM domain protein of the Ajuba/Zyxin family, which is enriched in the basal bodies of cells in the pronephros and Kupffer's vesicle in zebrafish (44). In zebrafish, wtip deletion leads to pronephric cysts, hydrocephalus, body axis curvature and pericardial edema (44); iv) cryptic deletion in the human wtip gene was reported to cause hypospadias, accompanied by congenital heart disease (45), but the roles for Wtip in the heart are unknown. Since Wtip plays a role in ciliopathy (44), interacts with wtl (40), which is expressed in the PE, and Wtip depletion leads to pericardial edema (44), we hypothesized that Wtip function in the heart may be associated with PE specification and may be involved in LR patterning.

In the present study, we show that cardiac expression of wtip mirrors wtla, tcf 21 , and tbx 18 expression, confirming that wtip is expressed in the PE. This is the first report, to the best of our knowledge, to describe how Wtip, a basal body protein, is important for PE specification, heart looping, AV formation and LR patterning.

\section{Materials and methods}

Zebrafish maintenance. All animal experiments were performed in strict accordance with the recommendations in the Guide for the Care and Use of Laboratory Animals of the National Institutes of Health and were approved by the Institutional Animal Care and Use Committee of the University of Oklahoma Health Sciences Center. Danio rerio $\left(\mathrm{AB}\right.$ strain) were maintained and raised at $28.5^{\circ} \mathrm{C}$ under a 14-h light/10-h dark cycle. Zebrafish embryos were kept in $0.5 X$ E2 egg medium $(7.5 \mathrm{mM} \mathrm{NaCl}, 0.25 \mathrm{mM} \mathrm{KCl}, 0.5 \mathrm{mM}$ $\mathrm{CaCl}_{2}, 0.5 \mathrm{mM} \mathrm{MgSO}{ }_{4}, 0.075 \mathrm{mM} \mathrm{KH} \mathrm{PO}_{4}, 0.025 \mathrm{mM}$ $\mathrm{Na}_{2} \mathrm{HPO}_{4}, 0.35 \mathrm{mM} \mathrm{NaHCO}, 0.01 \%$ methylene blue). To suppress pigmentation of zebrafish embryos, $0.0045 \%$ 1-Phenyl-2-thiourea (Sigma-Aldrich, St. Louis, MO, USA) was added to egg medium as needed. Embryos and larvae were staged according to h post-fertilization (hpf) or days post-fertilization (dpf) (46).

Morpholino and mRNA injections. A translational blocking morpholino oligonucleotide (MO) targeted against the 5'UTR of wtip (wtipMO; 5'-GAT CCT CGT CGT ATT CAT CCA TGT C-3'; 44), wtla (wtlaMO: 5'-GAG CAA GAG ATA CTG ACC TGA AGG C-3'; 22), and randomized control $M O$ (conMO: 5'-CCT CTT ACC TCA GTT ACA ATT TAT A-3') were obtained from Gene Tools, LLC (Philomath, OR, USA). A volume of $4.6 \mathrm{nl}$ with a concentration of $0.225 \mathrm{mM}$ wtipMO, $0.056 \mathrm{mM}$ wtipMO, $0.25 \mathrm{mM}$ wtlaMO $0.0625 \mathrm{mM}$ wtlaMO, and $92 \mathrm{pg}$ wtip mRNA was injected at the one-cell stage using a nanoliter 2000 microinjector (World Precision Instruments, Inc., Sarasota, FL, USA). Zebrafish wtip mRNA was synthesized with T7 RNA polymerase (Thermo Fisher Scientific, Inc., Waltham, MA, USA), after linearization of the pCR $^{\circledR}$-BluntII-TOPO ${ }^{\circledR}$-wtip construct with HindIII (Thermo Fisher Scientific, Inc.). All mRNAs were purified using the RNeasy Mini Kit (Qiagen, Inc., Valencia, CA). Microinjections into 1-cell embryos were performed as described by Feng et al (47). To knockdown wtip specifically in dorsal forerunner (DFCs), wtipMO was injected into the yolk cell of the $\sim 1,000$-cell stage embryos as previously described (48).

In situ hybridization. Whole-mount in situ hybridization was performed as previously described $(49,50)$, using the following probes: wtip, wtla, tcf $21, t b x 18, b m p 4$, LR determination factor 1 (lefty1), lefty2, southpaw (spaw), cardiac myosin light chain 2 (cmlc2), $\alpha$-cardiac myosin heavy chain (amhc), ventricular MHC (vmhc) and natriuretic peptide A (nppa) $(34,44,51-54)$. Polymerase chain reaction (PCR) DNA templates were used for wtla, tcf21, bmp4, lefty1, lefty2, spaw, $c m l c 2, a m h c, v m h c$ and $n p p a$. DNA templates were used for wtip and tbx18. We used the following primers to prepare the PCR DNA template for reverse transcription (RT)-PCR and 2nd PCR for wtla (765 bp): wtla-51F1 5'-CCG GTG GAA ACG GTA ACT GTA-3'; wtla-1161R1 5'-TCT GCA GTT GAA GGG CTT CTC-3'; wtla-240F2 5'-GCA CTT CTC CGG ACA GTT CAC-3'; and wt1a-1004R2T7 5'-GGT AAT 
ACG ACT CAC TAT AGG GAG AAC CTG CGA CCA CAG TCT-3'. For $t c f 21$ (682 bp), we used the following primers: tcf21-68F1 5'-TCA TCT CCA CGT CCA GTC AGA-3'; tcf21-876R1 5'-CAC ACT GTT GCC TTG AAC CAG-3'; tcf21-124F2 5'-TCT CCA CTC CAC CCT TGT CTC-3'; and tcf21-805R2T7 5'-GGT AAT ACG ACT CAC TAT AGG ATG CGA GTG AGG ATG TTG TCC-3'. The primers used for leftl (875 bp) were: leftyl-83F1 5'-ACG CTC TGC TGA AGA AAC TGG-3'; leftyl-1065R2 5'-AAT ATT GTC CAT TGC GCA TCC-3'; leftyl-153F2 5'-GAT CCC AAC GCA CGT AAA GAA-3'; and leftyl-1027R2T7 5'-GGT AAT ACG ACT CAC TAT AGG TGT TTG GGA ATT CAG CCA CTT-3'. Primers for lefty2 (807 bp) were: lefty2-31F1 5'-ACC ACA GCG ATC TCA CTC ACA-3; lefty2-1029R1 5'-TTC TGC CAC CTC GAT TTC AGT-3'; lefty2-35F2 5'-CAG CGA TCT CAC TCA CAC AGG-3'; and lefty2-841R2T7 5'-GGT AAT ACG ACT CAC TAT AGG TGA GCT CAC GGA AGT TGA TGA-3'. For spaw (656 bp), we used the following primers: spaw-210F1 5'-TAG TGT TGA CAA CCC GGC TCT-3'; spaw-1200R1 5'-CTC CTC CAC GAT CAT GTC CTC-3'; spaw-461F2 5'-AAC TGT TTC TGG GCA GCG TTA-3'; and spaw-1116R2T7 5'-GGT AAT ACG ACT CAC TAT AGG CAC CAC TCC ATC CCC TTC ATA-3'. The primers for $b m p 4$ (851 bp) were: bmp4-76F1 5'-CTG ATA CCC GAG GAA GGG AAG-3'; $b m p 4-1068 R 1$ 5'-CAC CGA GTT CAC CAG TGT CTG-3'; $b m p 4-84 F 2$ 5'-CGA GGA AGG GAA GAA GAA AGC-3'; and bmp4-934R2T7 5'-GGT AAT ACG ACT CAC TAT AGG CGT CGC TGA AAT CCA CAT ACA-3'. For $m y l 7$ (440 bp), we used: $m y l 7-25 F 1$ 5'-AAG AGG GGG GAA ACT GCT CAA-3'; myl7-518R1 5'-CAA GAT TCC TCT TTT TCA TCA CCA-3'; $m y l 7-27 F 2$ GAG GGG GAA AAC TGC TCA AAG-3'; and myl7-466R2T7 GGT AAT ACG ACT CAC TAT AGG AAT CAA TAT TTC CAG CCA CGT C. The following primers were used for $a m h c$ (939 bp): amhc-4486F1 5'-AGG CTC GCA GTT TAA GCA CTG-3'; amhc-5651R1 5'-CAA ATT CTT GCG ATC CTC GTC-3'; amhc-4614F2 5'-GTA AGC GAA GGG CGA AAG AGT-3'; and amhc-5552R2T7 5'-GGT AAT ACG ACT CAC TAT AGG AGC GTC CAG CTC ATT CTC AAG-3'. Primers for $v m h c(903 \mathrm{bp}$ ) were: $v m h c-3141 F 1$ 5'-GGC AAA AGC AAA GCT AGA GCA-3'; vmhc-4276Rl 5'-CGG TTT CCT GTA AGC GTT GAG-3'; vmhc-3258F2 5'-AAC CCA GGA AAG CCT AAT GGA-3'; and $v m h c-4160 R 2 T 7$ 5'-GGT AAT ACG ACT CAC TAT AGG GAC ATG CCT CGC TGT AGC TCT-3'.

All digoxigenin-UTP-labeled anti-sense RNA probes were synthesized using DIG-RNA (Sigma-Aldrich) labeling mix and T7 RNA polymerase (PCR DNA templates for wtla, tcf21, bmp 4, lefty1, lefty2, spaw, cmlc2, amhc, vmhc and nppa) or SP6 RNA polymerase (plasmid templates for wtip and tbx18; New England BioLabs, Inc., Ipswich, MA, USA), according to the manufacturer's instructions. Alkaline phosphatase-conjugated anti-digoxigenin (Sigma-Aldrich) was used to localize the probes (50). NBT/BCIP (Sigma-Aldrich) was used as the chromogenic substrate to produce blue precipitate. The zebrafish tbx18 DNA template was subcloned to pCR-BluntII-TOPO vector (Thermo Fisher Scientific, Inc.). Primers used to prepare DNA template for RT-PCR and 2nd PCR for $t b x 18$ (828 bp) were as follows: $t b x 18-14 F 1$ 5'-GAC GGT CCC CGT GTA CTA TGA-3'; tbx18-997R1 5'-TCC CAA GGA TGT CCT
CAA ATG-3'; $t b x 18-91 F 2$ 5'-AAA TTG GAG GAG GAG GAC AGC-3'; and $t b x 18-918 R 2$ 5'-CAT TCT GTT TCG TCC CGA GTC-3'. Finally, tbx 18 plasmid was linearized by Xhol and SP6 RNA polymerase, and wtip plasmid was linearized by NotI and SP6 RNA polymerase (44).

Cardiac looping assessments. The extent of cardiac looping was assessed in wtip morphants and buffer-injected control embryos using the $\operatorname{Tg}(m y l 7: E G F P)$ line. At $48 \mathrm{hpf}$, embryos were fixed in $4 \%$ formaldehyde, mounted in $1 \%$ agarose and were optimally positioned for cardiac imaging. The looping angle (LA) was defined as the angle between the anterior/posterior axis of the embryo and the cross-sectional plane of the AV junction (55). Student's t-test using an $\alpha$ of 0.05 was used to evaluate differences in looping angle means ( $\mathrm{n}=10$ hearts/treatment). Statistical analysis was performed using Microsoft Excel 2016 (Microsoft Corporation, Redmond, WA, USA).

Antibodies and whole-mount immunohistochemistry. A previously published protocol was followed $(44,56)$. Primary antibodies were: Custom-made anti-Wtip (1:100 dilution; Covance, Inc., Denver, PA, USA), anti- $\gamma$-tubulin (GTU-88; 1:800 dilution; Sigma-Aldrich), anti-acetylated $\alpha$-tubulin (6-11B-1; 1:800 dilution; Sigma-Aldrich), and anti-centrin (20H5; 1:1,000 dilution; EMD Millipore, Billerica, MA, USA). The following secondary antibodies were obtained from Thermo Fisher Scientific, Inc.: Goat anti-rabbit Alexa Fluor $^{\circledR} 546(\operatorname{IgG}[\mathrm{H}+\mathrm{L}])$, goat anti-mouse Alexa Fluor ${ }^{\circledR} 488$ (IgG2b), goat anti-mouse Alexa Fluor ${ }^{\circledR} 488$ [ $\left.\operatorname{IgG} 1(\gamma 1)\right]$, goat anti-mouse Alexa Fluor $^{\circledR} 488$ [IgG2a $\left.(\gamma 2 \mathrm{a})\right]$ and goat anti-mouse Alexa Fluor ${ }^{\circledR} 546$ [IgG1 ( $\left.\gamma 1\right)$ ]. Whole-mount immunohistochemistry samples were dehydrated with a graded series of methanol, embedded in JB4 resin (Polysciences, Inc., Warrington, PA, USA), and were cut into 5-7 $\mu \mathrm{m}$ sections using an RN2255 microtome (Leica Technology, Exton, PA, USA). The sections were stained with DAPI (Kirkegaard \& Perry Laboratories, Inc., Gaithersburg, MD, USA), mounted in Fluorescent Mounting Media (Kirkegaard \& Perry Laboratories, Inc.), and were imaged with a FV-1000 confocal laser-scanning microscope (Olympus America, Inc., Center Valley, PA, USA).

Histological analysis. Embryos were fixed with histology fixative $[1.5 \%$ glutaraldehyde, $4 \%$ formaldehyde, $3 \%$ sucrose in $0.1 \mathrm{mM}$ phosphate buffer (PB, $\mathrm{pH} 7.3)$ ] overnight at $4^{\circ} \mathrm{C}$. Fixed embryos were then dehydrated with a graded series of methanol and embedded in JB4 resin (Polysciences, Inc., Warrington, PA, USA). Sections $(4 \mu \mathrm{m})$ were cut with an RN2255 microtome (Leica Technology) and were stained with Harris hematoxylin and special eosin II (BBC Biochemical, Mount Vernon, WA, USA). Once the sections were mounted in Polymount (Polysciences, Inc.), the stained sections were imaged with a Provis AX-70 microscope (Olympus America, Inc.) equipped with a RETIGA EXi digital camera (QImaging, Surrey, Canada).

\section{Results}

Wtip expression in the cardiac region is identical to PE marker genes. WT1 is expressed in the PE and glomerulus podocytes in 
mammals, birds, zebrafish and medaka (22,57-61). In addition to wtla gene expression in zebrafish PE (22), the expression patterns of other PE markers, including $t c f 21$ and $t b x 18$, are well documented at $48 \mathrm{hpf}, 57 \mathrm{hpf}$, and 4 days post-fertilization (dpf) $(22,23)$. It was previously demonstrated that zebrafish embryos depleted for wtip via anti-sense morpholino (wtipMO) developed pericardial edema (44).

To investigate possible roles for Wtip in PE specification and development, whole-mount in situ hybridization was used (Fig. 1). Wtip mRNA was detected at $48 \mathrm{hpf}$ (Fig. 1A) and $4 \mathrm{dpf}$ (Fig. 1E) in zebrafish embryonic hearts. At 48 hpf, wtip-positive cells at the pericardial surface of the yolk were observed to be broadly dispersed at the AV-to-sinus venous region (Fig. 1A, yellow arrowhead marks the AV junction). By 4 dpf, wtip-positive cells appeared to have spread over the heart to cover the myocardium (Fig. 1E, yellow arrowhead). To determine the identity of the cells expressing wtip, the common PE marker genes wtla (Fig. 1B and F, yellow arrowheads), $t c f 21$ (Fig. $1 \mathrm{C}$ and $\mathrm{G}$, yellow arrowheads) and tbx18 (Fig. 1D and H, yellow arrowheads) were evaluated at $48 \mathrm{hpf}$ (Fig. 1A-D) and $4 \mathrm{dpf}$ (Fig. 1E-H). At 48 hpf, wtla, $t c f 21$ and $t b x 18$ expression was detected at the level of the sinus venous and adjacent to the AV junction (Fig. 1B-D, yellow arrowheads). At this stage, cardiac expression typically appears punctate, as would be expected for the isolated clumps of PE, which have not yet formed a uniform layer. In addition, $t c f 21$ expression occurred in the pharyngeal arch (Fig. 1C, black arrows), and tbx 18 expression occurred in the pectoral fin (Fig. 1D, asterisk). By $4 \mathrm{dpf}$, the wtla-, tcf 21 and $t b x 18$-positive cells spread over the heart to cover the myocardium (Fig. 1F-H, yellow arrowheads). Therefore, the wtip-positive cells exhibited an expression pattern similar to the known PE marker genes $w t l a, t c f 21$ and $t b x 18$, and corresponded in physical appearance to extracardiac cell populations, indicating their PE identity $(22,23)$.

To further assess a possible cell autonomous role for Wtip in the PE, the subcellular localization of this protein in the PE was examined using a zebrafish-specific anti-Wtip antibody (44). In a previous study, Wtip protein was observed to be enriched in the basal body, a structure that resides at the base of cilia in the pronephros, Kupffer's vesicle (KV) and other ciliated tissues (44). While cilia have not been reported in the zebrafish embryonic heart, they have been discovered in mouse (39) and chick hearts (62). Accordingly, the possibility that Wtip may localize to the basal body at the base of cilia in the zebrafish embryonic heart was considered. Therefore, double immunostaining was performed with antibodies against zebrafish Wtip and the cilia marker acetylated $\alpha$-tubulin (Fig. 1I and J), or the basal body marker $\gamma$-tubulin (Fig. 1K-M) and basal body marker centrin (Fig. 1N-P), in 48 hpf PE. Sagittal section staining suggested that Wtip was localized to the basal body of cilia located on PE in the $48 \mathrm{hpf}$ embryos (Fig. 1I-P). The specificity of the localization pattern was verified by knockdown of endogenous wtip expression with wtipMO (44), which abolished Wtip immunostaining (Fig. 1J). Together, these data provide the first evidence, to the best of our knowledge, that the zebrafish embryonic heart develops cilia and basal bodies (Fig. 1I-P). In addition, these data indicate that Wtip is expressed in the basal bodies of cells in the PE of the zebrafish embryonic heart.
Wtip signaling is required for PE specification.wtl null mutant mice develop cardiac abnormalities (16), and the epicardium fails to form properly (19). The $w t 1$ gene is expressed in both the epicardial lineage and in kidney podocytes, and this pattern is well conserved in mammals, zebrafish and medaka $(22,59,61,63)$. To test whether Wtip is required for PE formation and specification during zebrafish embryonic heart development, a wtip morpholino antisense oligonucleotide (MO) was used to inhibit translation of wtip transcripts (44). First, the PE formation in 48 hpf wtip knockdown embryos was examined (Fig. 2) using the PE-specific markers $t c f 21$ (Fig. 2B, $\mathrm{C}$ and $\mathrm{G}$ ) and $t b x 18$ (Fig. 2E, F and H). Injection of wtipMO produced embryos with body axis curvature, pronephric cysts, hydrocephalus and pericardial edema. Approximately $99 \%$ of injected embryos $(n=64)$ developed pericardial edema. In wtip knockdown embryos, the expression of $t c f 21$ and $t b x 18$ in the heart was found to be significantly reduced $(25 / 36,69.4 \%$ for tcf 21 and 14/27, 51.9\% for tbx 18; Fig. 2B, E, G and H, yellow arrowheads) or absent $(11 / 36,30.6 \%$ for $t c f 21$ and $13 / 27,48.1 \%$ for tbx18; Fig. 2C, F, G and H, yellow arrowheads). By contrast, despite modest developmental delay $(2 \mathrm{~h})$ in these embryos, $t c f 21$ expression in the pharyngeal arch (Fig. 2B and C, black arrows) and tbx 18 expression in the pectoral fin were unaffected (Fig. 2E and F, asterisk). These data indicate that Wtip signaling is essential for early epicardial development and is required to specify the $\mathrm{PE}$.

To determine whether Wtip signaling is sufficient to induce PE marker gene expression, wtip mRNA was overexpressed (Fig. 3). In embryos with ubiquitous wtip mRNA expression, ectopic $t c f 21$ (34/34, 100\%; Fig. 3B, black arrows) and $\operatorname{tb} x 18(31 / 31,100 \%)$ expression was observed in the heart region (Fig. 3D, black arrows) compared with control tcf 21 ( $n=26$; Fig. 3A) and $t b x 18$ ( $n=26$; Fig. 3C) expression in the PE region of the heart (yellow arrowheads indicate sinus venous). In all of the wtip mRNA-overexpressing embryos, ectopic clusters of the $t c f 21$ - and $t b x 18$-positive cells were observed, which appeared more widespread and numerous than the clusters seen in wild-type embryos. Occasional ectopic clusters were located in or near the craniofacial area (Fig. 3B and D, black arrows), and were consistently observed in the cardiac region. Overexpression of wtip mRNA in embryos did not affect $t b x 18$ expression in the pectoral fin (Fig. 3C and D, black asterisk).

Wtip and wtla functionally interact during PE development. Mouse wtip was originally identified as an interacting partner of $w t 1$ in a yeast two-hybrid screen (40). However, the implications of the potential interation between Wtip and WT1 in PE formation have not been reported. The co-expression of wtla (Fig. 1B and F, yellow arrowhead; 22) and wtip (Fig. 1A and E, yellow arrowhead) in PE control embryos, along with the similar cardiac phenotypes generated by knockdown of either gene, support the notion that these two genes may function together in zebrafish PE formation. In wtla morphants (Fig. 4), the expression of PE markers was reduced $(7 / 47,14.9 \%$ for $t c f 21$, Fig. 4M; and 3/33, 9.1\% for tbx18; Fig. 4N) or absent $(40 / 47$, $85.1 \%$ for $t c f 21$, Fig. $4 \mathrm{G}$ and M, black arrows; and 30/33, $90.9 \%$ for tbx18; Fig. 4M and N, black arrows). As described (Fig. 2B, C, E-H), in wtip morphants, PE markers were similarly reduced (21/30, 70\% for tcf 21 , Fig. 4M; and 13/25, 52\% for $t b x 18$, Fig. $4 \mathrm{~N})$ or absent $(9 / 30,30 \%$ for $t c f 21$, Fig. $4 \mathrm{C}$ and M, black 
$\mathbf{A}$
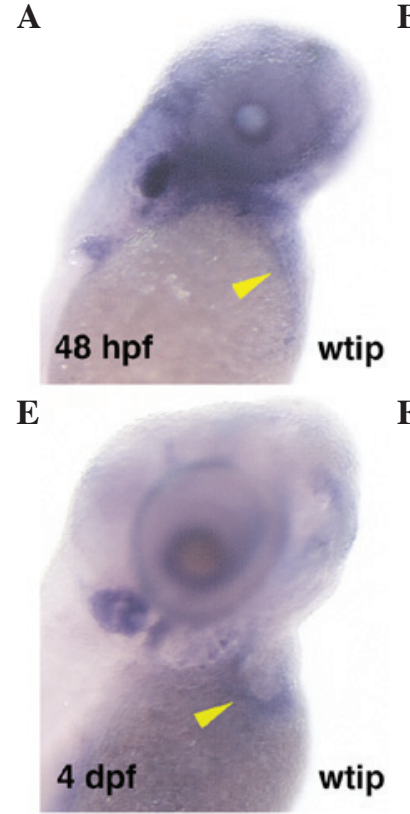

I

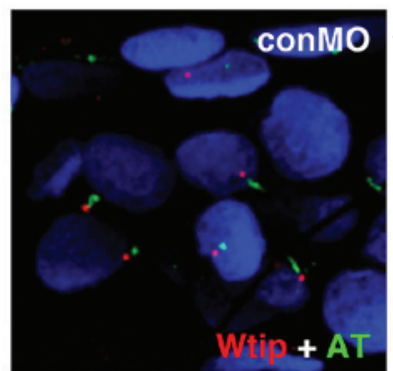

B

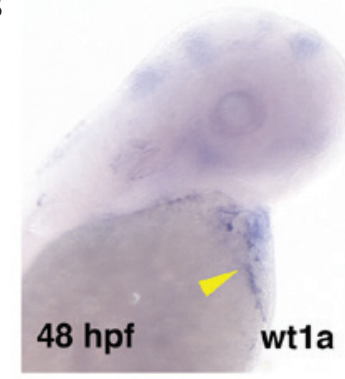

F

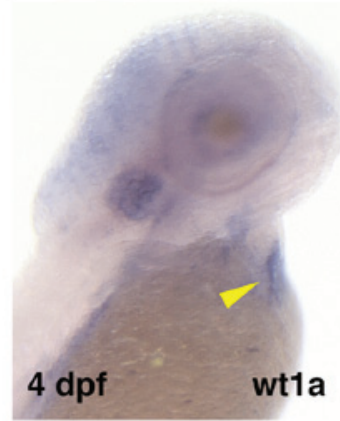

C

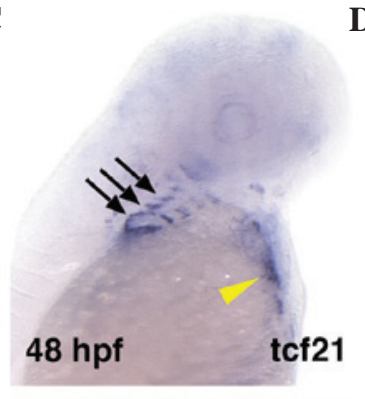

G

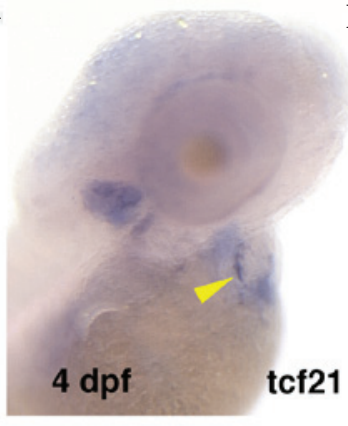

D

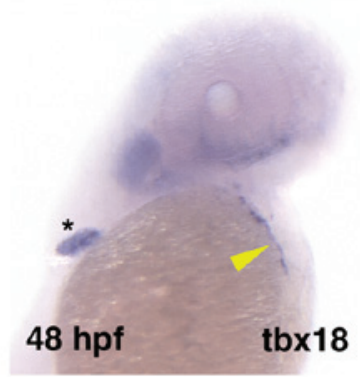

H

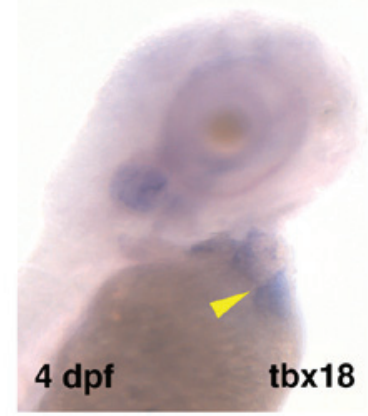

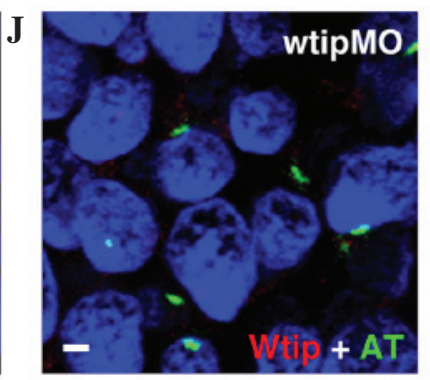
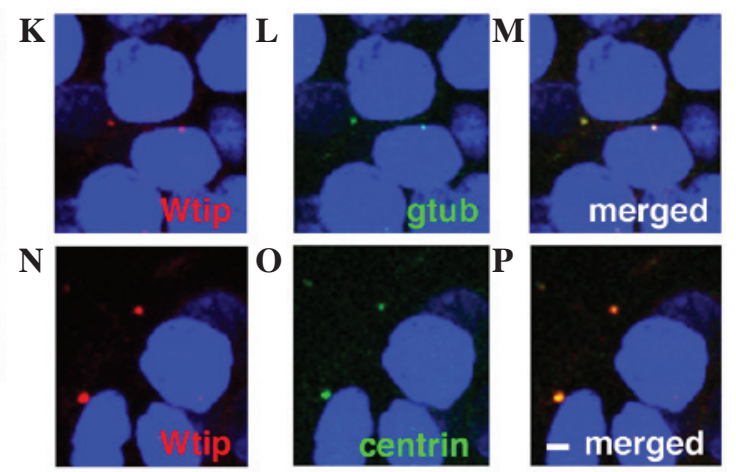

Figure 1. wtip expression is identical to PE-specific markers during zebrafish heart development. Lateral view of (A-D) $48 \mathrm{hpf}$ and (E-H) $4 \mathrm{dpf}$ whole-mount in situ hybridization of (A,E) wtip, (B,F) wtla, (C,G) tcf21 and (D,H) tbx18. At 48 hpf, (A) wtip, and PE markers (B) wtla-, (C) tcf21- and (D) tbx18- positive cells were in the clusters near the sinus venosus, between the atrium and the yolk and near the AV junction, in contact with the ventral surface of the heart (yellow arrowhead in A-D). At $48 \mathrm{hpf}, t c f 21$ expression occurred in the pharyngeal arch (black arrows in C) and tbx 18 expression occurred in the pectoral fin (black asterisk in D). By 4 dpf, the wtla-, tcf21- and tbx18-positive cells spread over the heart to cover the myocardium (yellow arrowhead in F-H). By 4 dpf, wtip-, tcf21- and tbx18-positive cells appeared to spread over the heart to cover the myocardium along the dorsal surface of the heart (yellow arrowhead in E-H). (I,J) Double immunofluorescence for the cilia marker acetylated $\alpha$-tubulin (green) and Wtip (red) in confocal projections of the zebrafish PE at 48 hpf. (J) No Wtip signal was detectable in wtipMO knockdown embryos, confirming antibody specificity. (K-P, red) Localization of Wtip in the basal bodies of cilia was confirmed by double immunostaining with Wtip antibody and either (L,M, green) anti- $\gamma$-tubulin or (O,P, green) anti-centrin, which are basal body markers in heart. 4',6-diamidino-2-phenylindole was used to counterstain nuclei (blue). Scale bar=10 $\mu \mathrm{m}$. wtip, Wilms tumor 1 interacting protein; PE, proepicardial organ; hpf, hours post-fertilization; dpf, days post fertilization; wt la, Wilms tumor 1a; $t c f 21$, transcription factor 21; tbx18, Tbox 18; wtipMO, wtip morpholino oligonucleotide; conMO, control MO; AT, acetylated $\alpha$-tubulin.

arrow; and 12/25, 48\% for tbx18, Fig. 4D, and N, black arrow). To further investigate the potential for Wtip and WT1 interaction, a combined knockdown of wtip and wtla was performed using sub-threshold doses of both morpholinos to assess whether a genetic interaction between these proteins would alter the expression of the PE markers $t c f 21$ and $t b x 18$. Prior to this, the appropriate sub-threshold doses for each morpholino was determined: i) $w t 1 a M O, n=28$ for $t c f 21$ (Fig. 4I and M, yellow arrowhead) and $n=27$ for $t b x 18$ (Fig. 4J and M, yellow arrowhead) and ii) wtipMO, $n=36$ for $t c f 21$ (Fig. 4E and M, yellow arrowhead) and $n=35$ for $t b x 18$ (Fig. 4F and M, yellow arrowhead). Sub-threshold doses for either morpholino alone had no effect on $t c f 21$ (Fig. 4E, I and M, yellow arrowhead) or tbx 18 (Fig. 4F, J and N, yellow arrowhead) expression in the PE: wtlaMO, 26/28, 92.9\% for tcf 21 (Fig. 4I and M, yellow arrowhead) and 25/27, 92.6\% for $t b x 18$ (Fig. 4J and N, yellow arrowhead); wtipMO, 34/36, $92.9 \%$ for $t c f 21$ and 33/35, $94.3 \%$ for tbx18 (Fig. 4E, F, M and N, yellow arrowhead). However, in wtip and wtla double morphants, $t c f 21$ and $t b x 18$ expression was severely reduced (3/27, $11.1 \%$ for $t c f 21$, Fig. 4M; and $3 / 32,9.4 \%$ for $t b x 18$, Fig. $4 \mathrm{~N})$ or absent $(24 / 32,88.9 \%$ for $t c f 21$, Fig. 4K and M, black arrow; and 29/32, 90.5\% for $t b x 18$, Fig. 4L and N, black arrow) in the cardiac region. These data indicate that Wtip is genetically associated with Wt1a, and that together they influence PE specification.

Wtip is required for cardiac looping and valve formation, but not for chamber patterning. Cardiac looping is a morphogenic process in vertebrates. This process re-shapes the linear heart tube by bending the cardiac chambers into close juxtaposition. In zebrafish, cardiac looping begins around $30 \mathrm{hpf}$ as the heart tube folds, gradually bringing the atrium 
A

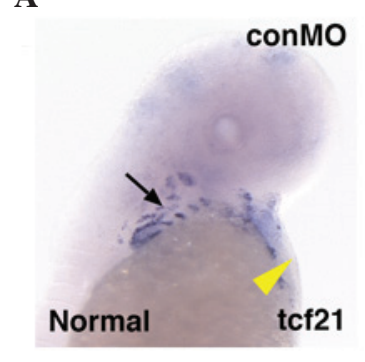

D

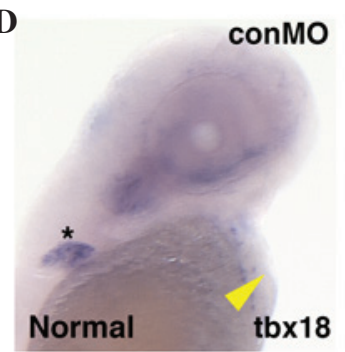

B

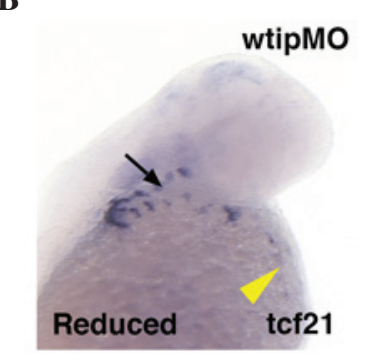

E

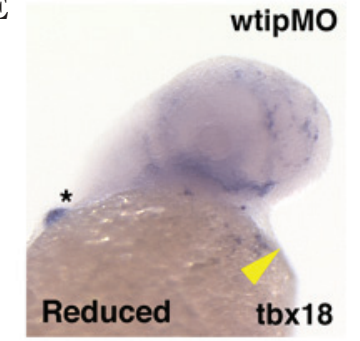

C

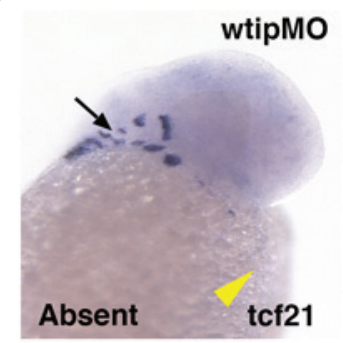

$\mathbf{F}$

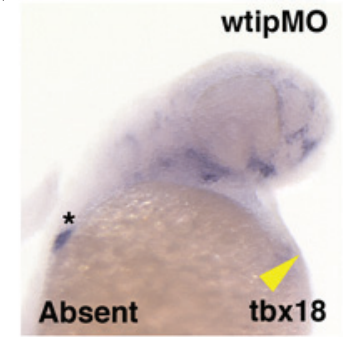

G

tcf21

$\mathbf{H}$

tbx18
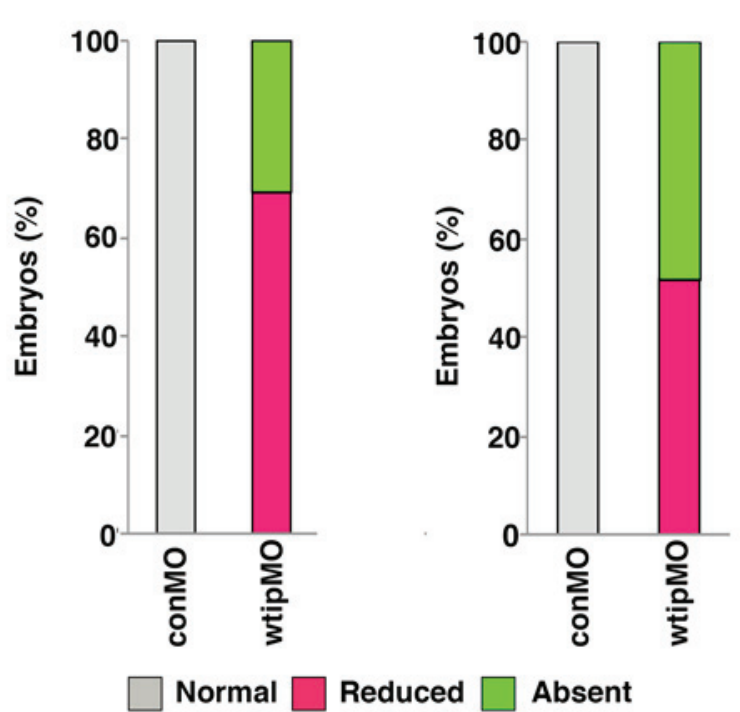

Figure 2. Wtip is required for PE specification. Ventral view of 48 hpf whole-mount in situ hybridization of (A-C) tcf21 and (D-F) tbx 18 in (A,D,G,H)control (1.035 pmol/embryo) and (B,C,E-H) wtip morphant embryos (1.035 pmol/embryo). Both $t c f 21$ and tbx 18 express specifically in the PE in the control embryos (yellow arrowhead in A, D), but is reduced or absent in wtip morphant embryos. tcf21 expression in the pharyngeal arch (black arrow in A-C) and tbxl8 expression in the pectoral fin (black asterisk in D-F) in wtip morphants are unaffected. wtip, Wilms tumor 1 interacting protein; PE, proepicardial organ; hpf, hours post fertilization; $t c f 21$, transcription factor 21; tbx18, Tbox 18; conMO, control morpholino oligonucleotide.

and ventricle into a side-by-side position by $48 \mathrm{hpf}(15,37)$. The continued bending of the heart tube, accompanied by chamber ballooning ( 48-58 hpf) (64), and concentric growth within the chambers (65), substantially remodels the shape of the heart by 72 hpf. Functionally, the organ changes rapidly over this period, as heart rate and cardiac output increase steadily $(3,66,67)$. Blood flow, which initially incorporates some back-flow through the AV junction, becomes consistently unidirectional as endocardial cushions and AV valves develop (68). Transgenic $T g(m y l 7: E G F P)$ embryos, which express GFP in the embryonic heart, provided easy visualization of the heart (Fig. 5A and B). As a simple rubric to describe the progression of cardiac looping in wtip morphants, the cardiac 'looping angle' was measured, defined as the degree of difference in the anterior/posterior $(\mathrm{A} / \mathrm{P})$ body axis and the plane of the AV junction (Fig. 5C) (55). At $48 \mathrm{hpf}$, control hearts exhibited an average looping angle of $16^{\circ}$, whereas looping angles in embryos injected with wtipMO were significantly larger, indicating that they were less looped (Fig. 5A-D). These data indicate that cardiac looping was impaired by Wtip depletion.

Next, it was examined whether the cardiac looping defect of wtip morphants was due to improper establishment of cardiac patterning. At $48 \mathrm{hpf}$, wtip morphants showed normal expression of the cardiac chamber-specific markers myl7 (cmlc2) (Fig. 5E-H), amhc (Fig. 5I-L) and vmhc (Fig. 5M-P). By 48 hpf, hearts in wild-type embryos have initiated cardiac looping, which shifts the ventricle to the right of the atrium (Fig. 5E, I and M). In the process of checking the heart patterning, a role for Wtip in differentiating the AV boundary 

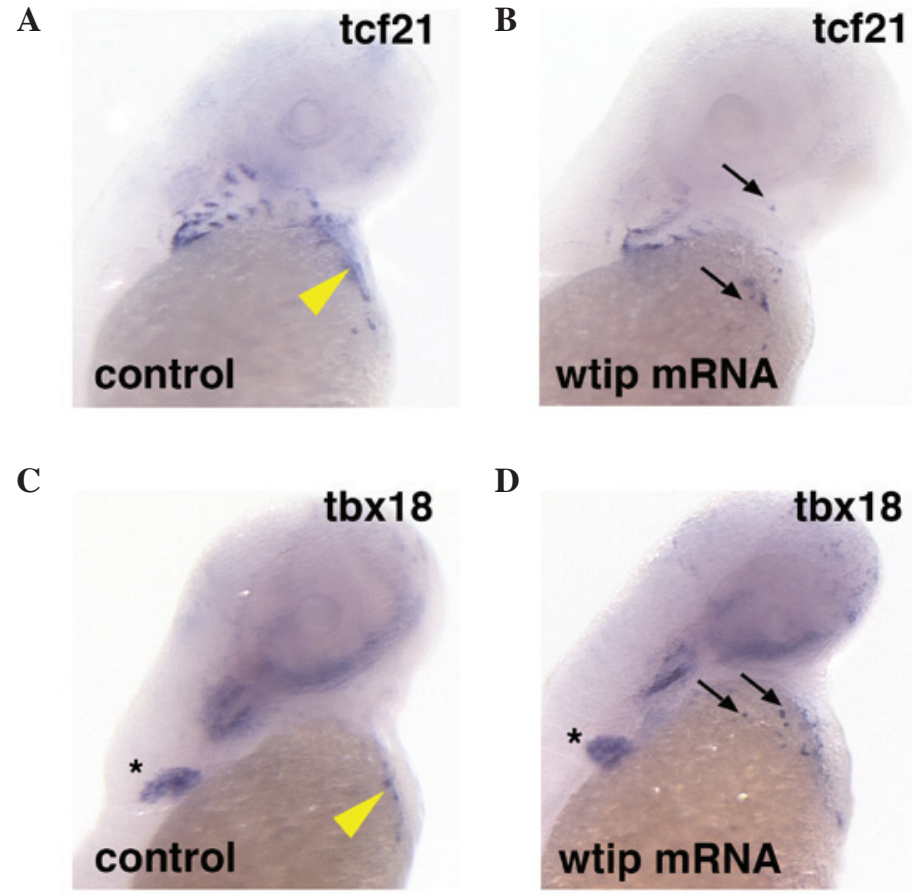

Figure 3. Ectopic expression of $t c f 21$ and $t b x 18$ in the cardiac and pharyngeal arch regions by wtip mRNA overexpression. Ventral view of 48 hpf whole-mount in situ hybridization of (A,B) tcf 21 and (C,D) tbx18) in (A,C) control and (B.D) wtip mRNA-injected embryos (92 pg/embryo). The ectopic expression of $t c f 21$ (black arrows in B) and $t b x 18$ (black arrows in D) expression in the heart region compared with control $t c f 21$ (yellow arrowhead in A) and $t b x 18$ (yellow arrowhead in $\mathrm{C}$ ) expression in the PE region of the heart. tbx18 expression in the pectoral fin (black asterisk in C) was unaffected in wtip mRNA-injected embryos. $t c f 21$, transcription factor 21; tbx18, Tbox 18; wtip, Wilm's tumor 1 interating protein; hpf, hours post fertilization; PE, proepicardial organ.

was identified. At 52 hpf, nppa was detected in both the ventricle and atrium but was absent from the AV boundary in wild-type embryos (Fig. 5Q, black arrows). Conversely, nрpa was detected throughout the heart, with no distinguishable exclusion from the AV boundary in wtip knockdown embryos (Fig. 5R). Analysis of sections (Fig. 6) revealed a thinned myocardial layer in the atrium, and increased separation of the myocardium and endocardium in the ventricle (Fig. 6B and E). Rather than transitioning to the expected cuboidal shape, AV endocardial cells in wtip knockdown embryos retained a squamous appearance at $72 \mathrm{hpf}$, and clear leaflets did not form (Fig. 6E). Importantly, the lack of AV boundary, thinned myocardial layer in the atrium, and increased separation of the myocardium and endocardium in the ventricle phenotype of wtip morphants could all be rescued by the co-injection of wtip mRNA, demonstrating that the phenotypes specifically result from wtip knockdown (Fig. 6C and F).

Knockdown of wtip results LR asymmetry defects. Ajuba LIM proteins (LIMD1, WTIP, AJUBA) are categorized as a family of LIM domain proteins, however, their functional similarities remain unclear. Embryos depleted for the Ajuba homolog in medaka (69) and zebrafish (70) exhibited developmental abnormalities, including LR patterning defects. It has been previously shown by in situ hybridization that wtip is expressed in a broad range of tissues during the gastrula period and early somitogenesis (44), including $\mathrm{KV}$, which is equivalent to the mammalian node in teleosts (71-73). Furthermore, Wtip protein expression was investigated by immunostaining using a zebrafish-specific Wtip antibody, which localized to the basal bodies of pronephros, KV and ciliated tissues (44). The wild-type heart typically 'jogs' to the left and subsequently loops to the right (34). To investigate the establishment of the LR axis within the forming zebrafish heart tube, bmp 4 expression was examined (Fig. 7), which is normally expressed predominantly on the left side of the cardiac cone $(118 / 118,100 \%$; Fig. 7I and M) (34). It was observed that wtip depletion caused embryos to exhibit bilateral bmp4 expression (85/118, 72\%; Fig. 7J and M). The heart tube of wtip morphants never underwent looping as occurred in control embryos at $48 \mathrm{hpf}$, which may reflect altered left-right patterning of the body (Fig. 5A-D, G, K, $\mathrm{O}$ and $\mathrm{R})$. Next, it was checked whether Wtip regulates not only bmp4, but also other early LR asymmetry markers in zebrafish. The left1/2 and southpaw (spaw) genes encode TGF- $\beta$ superfamily proteins that are expressed in the left lateral plate mesoderm in wild-type embryos. These early laterality markers are essential for the establishment of LR asymmetry in zebrafish (53). To investigate whether Wtip regulates zebrafish LR patterning by modulating the formation and/or function of $\mathrm{KV}$, wtipMO was injected into the yolk at the early blastula stage (128-cell stage) to target the precursors of KV (DFCs) and left1/2 (Fig. 7A-D, K) and spaw (Fig. 7E-H, L) expression patterns were examined. Injection of wtipMO led to randomization of the LR axis, as shown by left1/2 (Fig. 7A-D, K) and spaw (Fig. 7E-H, L) gene expression in the lateral plate mesoderm at $20 \mathrm{hpf}$. All control embryos displayed a left-sided left1/2 (118/118, 100\%) and spaw (180/180, 100\%) expression (Fig. 7A, E, K and L). By contrast, wtip morphants exhibited the full range of possible expression patterns: Left-sided expression (left1/2, 111/159, 
A

conMO

C

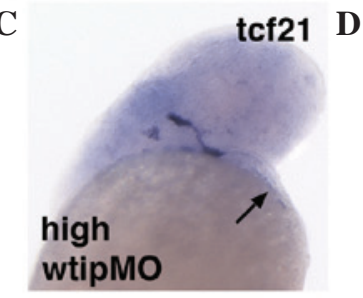

$\mathbf{E}$

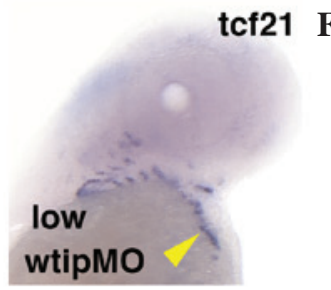

G

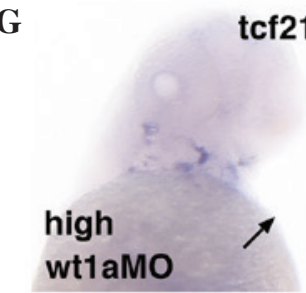

I

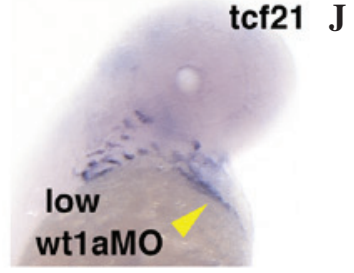

$\mathbf{K}$

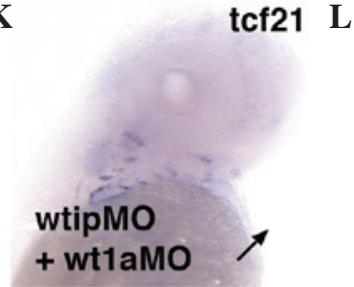

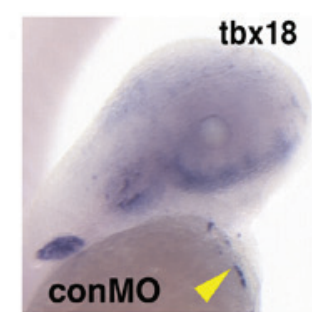

tbx18

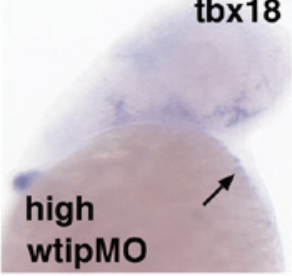

tbx18

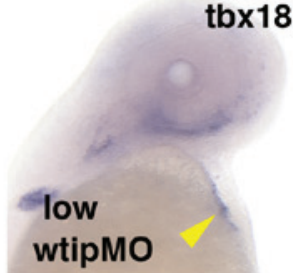

tbx18

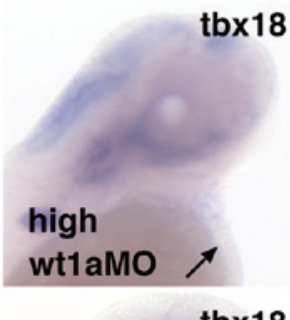

tbx18

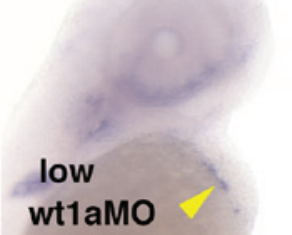

tbx18

M tcf21

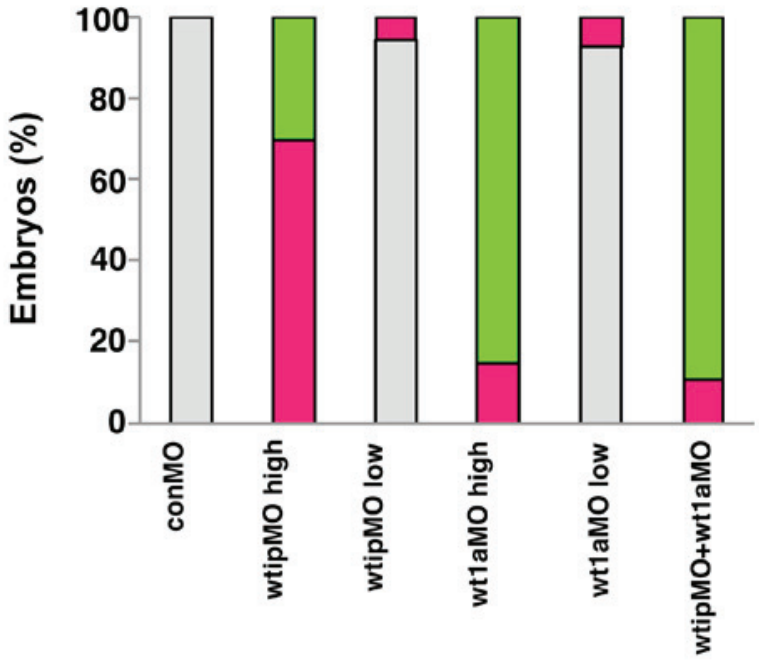

$\mathbf{N}$

tbx18

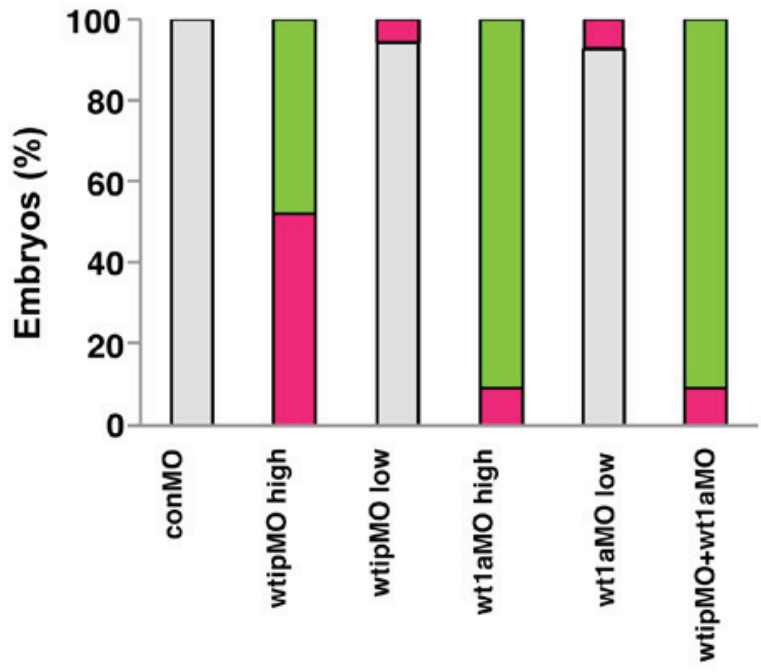

Normal $\square$ Reduced $\square$ Absent

Figure 4. Wt1a and Wtip cooperate for PE formation. Ventral view of 48 hpf whole-mount in situ hybridization of (A,C,E,G,I,K) $t c f 21$ and (B,D,F,H,J,L) tbx 18 expression in control (yellow arrowhead, A,B), high concentration of wtipMO (black arrow, C,D; 1.035 pmol/embryo), sub-threshold concentration of wtipMO (yellow arrowhead, E,F; 0.259 pmol/embryo), high concentration of wtlaMO (black arrow, G,H; 1.15 pmol/embryo), sub-threshold concentration of wtlaMO (yellow arrowhead, I,J; wtlaMO, 0.288 pmol/embryo), sub-threshold concentrations of wtlaMO (1.15 pmol/embryo)+wtipMO (0.259 pmol/embryo; black arrow, K,L) in PE at 48 hpf. With high concentrations of wtlaMO, PE marker expressions were reduced or absent (black arrow, for tcf21; G,M, and for $t b x 18 ; \mathrm{H}, \mathrm{N}$ ). With wtipMO, PE marker expressions were reduced (for $t c f 21, \mathrm{M}$ and for $t b x 18, \mathrm{~N}$ ) or absent (black arrow, for $t c f 21$; C,M, and for $t b x 18$; D,N). Sub-threshold doses for each MO had no effect on $t c f 21$ (yellow arrowhead, E,I,M) or tbx18 (yellow arrowhead, F,J,N) expression in PE. In the wtip and wt1a double morphants, $t c f 21$ and $t b x 18$ were severely reduced (black arrow, for $t c f 21 ; \mathrm{K}, \mathrm{M}$ and for $t b x 18$; L,N) or no longer expressed (for $t c f 21$ and for $t b x 18$ ) in the cardiac region. These data indicate that Wtip is associated with Wt1a and influences PE specification. Wt1a, Wilm's tumor 1a; Wtip, Wilm's tumor 1 interacting protein; PR, proepicardial organ; hpf, hours post fertilization; tcf21, transcription factor 21; tbx 18, Tbox 18; wtipMO, wtip morpholino oligonucleotide.

69.8\%; spaw, 120/185, 64.9\%), bilateral expression (left $1 / 2$, 6/159, 3.8\%; spaw, 37/185, 20\%), right-sided expression (left1/2, 4/159, 2.5\%; spaw, 14/185, 7.5\%), and no expression (left1/2, 38/159, 23.9\%; spaw, 14/185, 7.5\%; Fig. 7A-H, $\mathrm{K}$ and $\mathrm{L}$ ). These data suggest that Wtip signaling is required for early LR asymmetry.

\section{Discussion}

In humans, a wide range of cardiovascular defects is associated with kidney cystic disease, although the etiology of these abnormalities remains unclear. Similar to humans, pericardial edema in zebrafish is often observed in kidney cystic mutants 
C

A

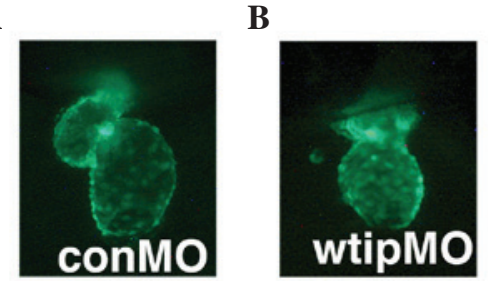

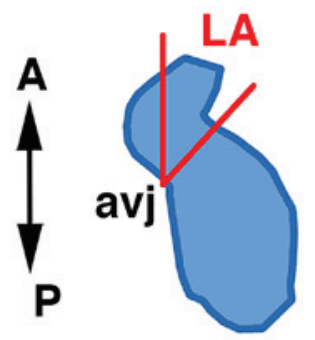

D

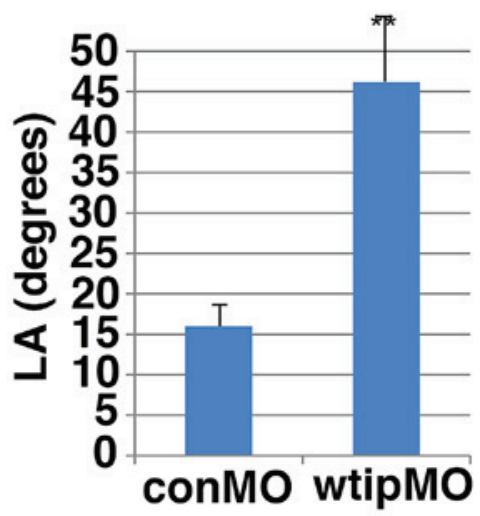

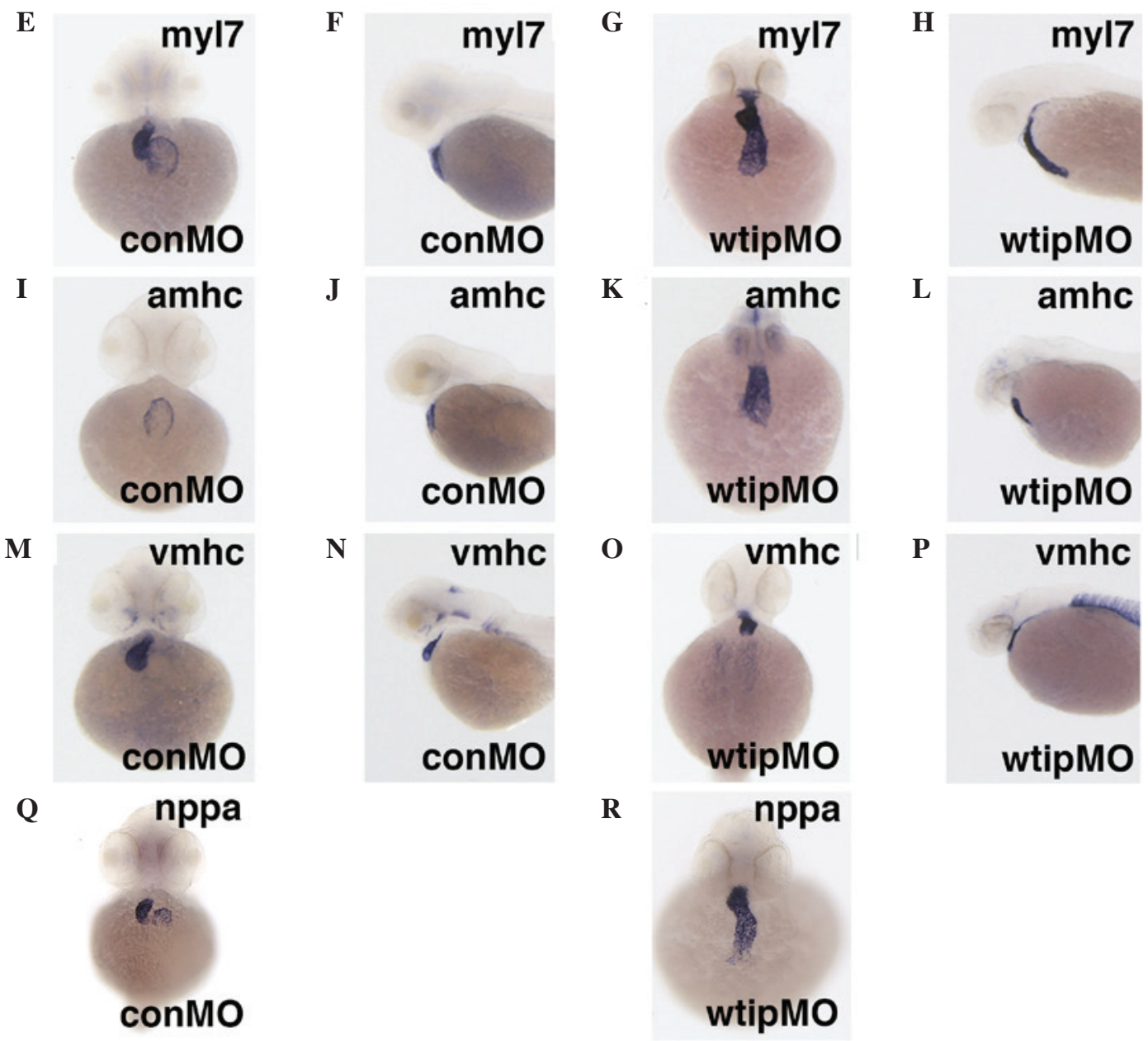

Figure 5. Wtip is required for AV boundary formation, but does not affect chamber patterning. Hearts of transgenic $T g(m y l 7: E G F P)$ embryos were visualized in $48 \mathrm{hpf}$ (A) control or (B) wtip morphant embryos (1.035 pmol/embryo) to assess the extent of cardiac looping. (C) Diagram depicting the cardiac LA, defined as the degree of difference in the anterior/posterior body axis and the plane of the AV junction. (D) Wtip depletion decreases the mean LA by 48 hpf. The mean \pm standard error is shown. ${ }^{*} \mathrm{P}<0.000359 . n=10$ embryos/treatment. 48 hpf whole-mount in situ hybridization in (E,F,I,J,M,N,Q) control and (G,H,K,L,O,P,L) wtip morphant embryos (1.035 pmol/embryo) of (E-H) $m y l 7$, (I-L) amhc, (M-P) vmhc and (Q,R) $n p p a$. (E,G,I,K,M,O,Q,R) Ventral view and $(\mathrm{F}, \mathrm{H}, \mathrm{J}, \mathrm{L}, \mathrm{N}, \mathrm{P})$ lateral view. Wtip does not regulate chamber patterning, but regulates nppa expression to maintain chamber myocardium expression and exclusion from the myocardium of the AV boundary. Wtip, Wilm's tumor 1 interacting protein; AV, atrioventricular; myl7, myosin light chain 7; EGFP, enhanced green fluorescent protein; hpf, hours post fertilization; LA, looping angle; amhc, $\alpha$ myosin heavy chain; vmhc, ventricular myosin heavy chain; $n p p a$, natriuretic peptide A; conMO, control morpholino oligonucleotide; A, anterior; $\mathrm{P}$, posterios; avj, AV junction.

or MO-mediated knockdown embryos $(74,75)$. However, the specific roles of cilia and basal bodies in PE, heart morphogenesis and function during normal development, and congenital heart disease (CHD) remain unknown $(37,76)$. Compared to myocardium and endocardium, relatively little is known about how PE develops and differentiates. The PE is an extra-cardiac source for several cardiac cell types, and increasing evidence suggests that the PE plays a role in heart development, repair of cardiac injury and ingrowth of coronary vessels (5-12). Despite the potentially central role of the epicardium in all of these 


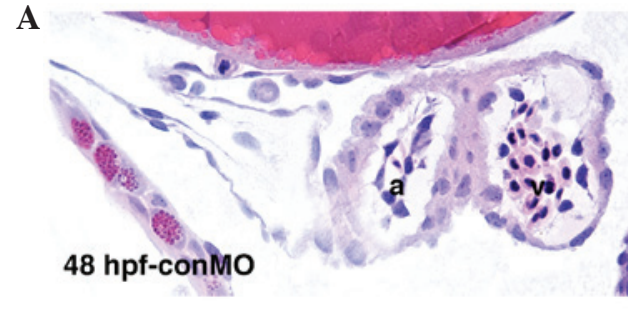

$\mathbf{B}$
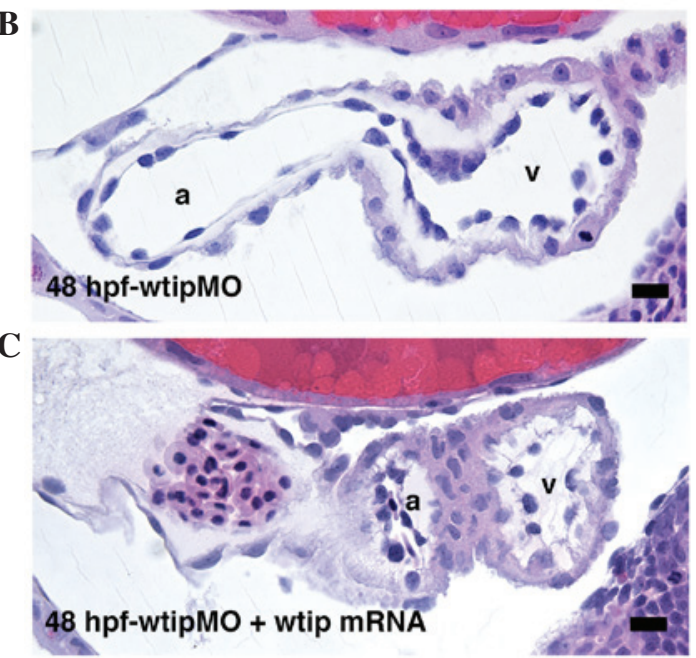

D

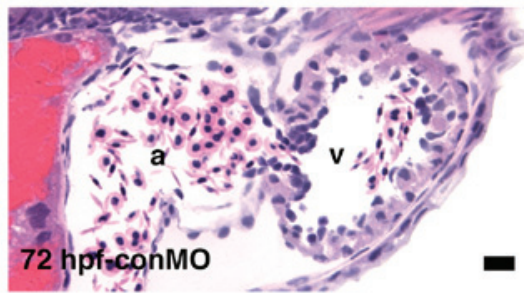

$\mathbf{E}$

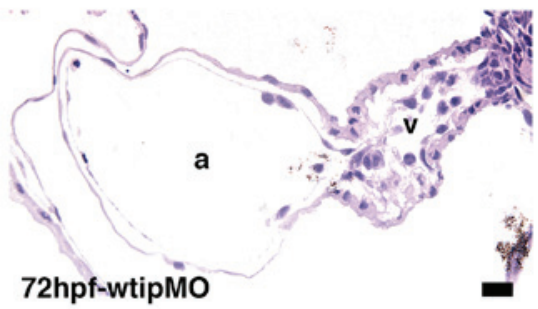

$\mathbf{F}$

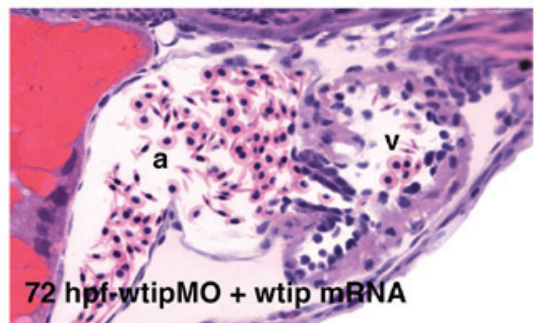

Figure 6. Wtip is required for proper valve development. Sagittal histological section of (A-C) 48 hpf and (D-F) 72 hpf zebrafish embryo hearts. (B,E) wtip morphants (1.035 pmol/embryo) display pericardial edema and (C,F) wtip mRNA (92 pg/embryo) can rescue pericardial edema. Scale bar=10 $\mu$ m. Wtip, Wilm's tumor 1 interacting protein; hpf, hours post fertilization; conMO, control morpholino oligonucleotide.

processes, the molecular signals driving the specification and morphogenesis of PE remain poorly understood. In the present study, the role of Wtip in PE development was investigated and genetic evidence presented that WT1, in association with Wtip, is required for PE specification. We further revealed a critical role for Wtip in heart looping and the establishment of the AV boundary. Based on the expression pattern of wtip mRNA and protein, blocked Wtip function, and wtip over-expression data, it is proposed that Wtip is required at early somite stages to provide LR asymmetry, and independently regulates later cardiac development, including heart-looping, PE specification and differentiation of the AV boundary.

Wtip was originally identified as an interacting partner of WT1 in a yeast two-hybrid screen (40). WT1 is expressed in the PE and glomerulus podocytes in mammals, birds, zebrafish and medaka (22,57-61). It was previously reported that depletion of the Wtip basal body was associated with the development of pronephric cysts, with it noted that these embryos also developed pericardial edema (44). Previously, cryptic deletion in the human wtip gene was reported to cause hypospadias (urethra malformation in males) that can be associated with congenital heart disease (45). Therefore, we predicted that pericardial edema in wtip knockdown embryos may be due to PE defects.

In the present study, a critical role of Wtip in PE specification during heart development was identified. It was demonstrated that wtip shows cardiac expression in PE at $48 \mathrm{hpf}$ and $4 \mathrm{dpf}$, in a pattern that specifically matches that of known PE-specific genes wtla, tcf 21 , and $t b x 18(22,23)$. Additionally, it was confirmed that the PE contains ciliated cells, and that Wtip localizes to the basal bodies within these cells in $48 \mathrm{hpf}$ embryos, as was the case for ciliated cells in the pronephros and Kupffer's vesicle (44). This is the first evidence that the zebrafish embryonic heart develops cilia and basal bodies during embryonic development. Furthermore, it was observed that depletion of wtip leads to the severe reduction or absence of PE formation and that Wtip and wtla cooperate for PE formation. By overexpressing wtip mRNA, ectopic expression of PE-specific markers was observed in the cardiac region and in the pharyngeal arch area. Based on wtip gene and protein expression patterns and on phenotypes generated by blocking Wtip function, it is proposed that Wtip is required initially to establish early LR asymmetry, and later to form the $\mathrm{PE}$, modulate heart looping and promote AV differentiation.

Recently, the PE has been investigated for its role in normal heart morphogenesis $(13,15,77)$ and additional capacity to form coronary vascular endothelial cells in mice (20). Zebrafish are now well established as a key model system for embryonic heart development and function, and possess a natural capacity for adult myocardial regeneration (78). To directly examine the possible critical roles for Wtip or the PE in response to injury and myocardial regeneration in adults, we would need to further consider using wtla, $t c f 21$ or $t b x 18$ transgenic lines (24-26).

A previous study reported that cells with primary $9+0$ cilia were found in both the embryonic and the adult human heart (79). Previous studies revealed that monocilia are found in the mouse embryonic heart at embryonic day (e) e9.5-e12.5, by which time blood flow is present $(39,76)$. The data suggest that in zebrafish embryos, cilia occur in the PE by 48 hpf, a similar stage to what has been observed in the chick embryonic heart (62). Previous reports suggest 
A

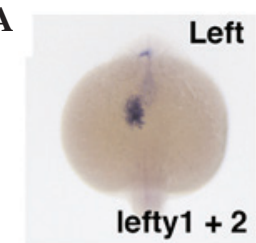

E

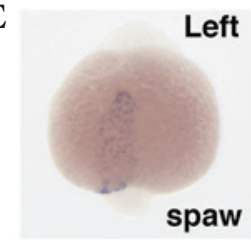

I

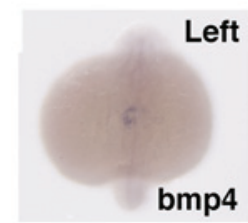

B

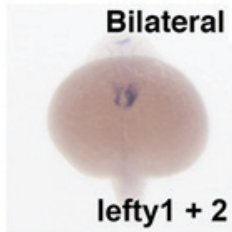

F

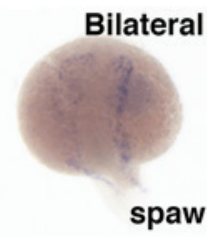

C

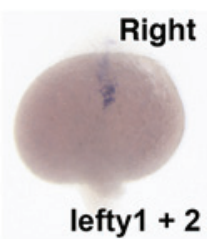

G

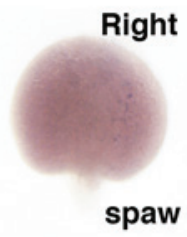

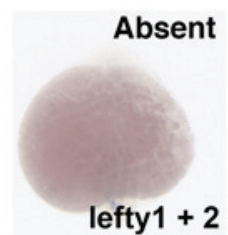

H

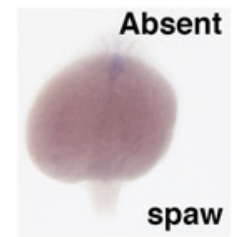

K

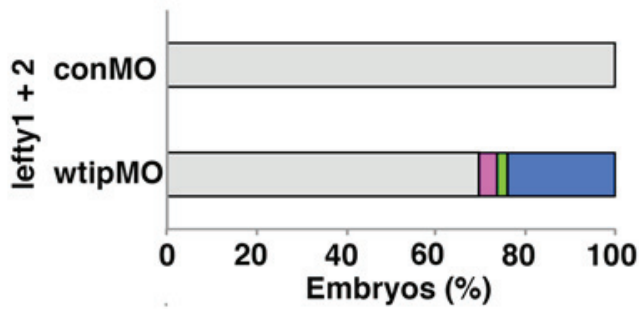

M

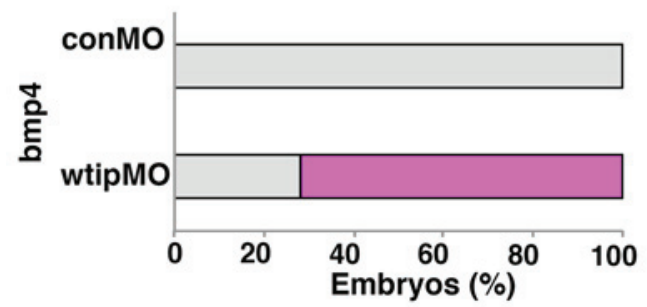

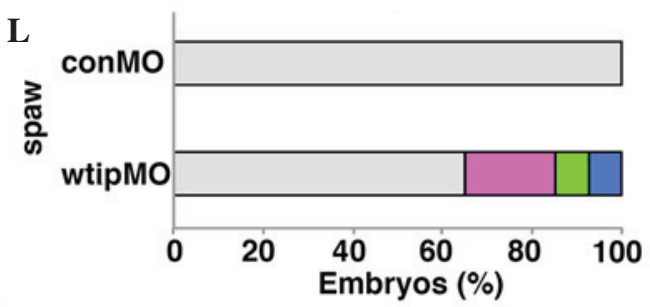

Left $\square$ Bilateral $\square$ Right $\square$ Absent

Figure 7. Wtip is required for early left-right patterning. Dorsal views, anterior to the bottom of the panels. (A-D,K) lefty1 and lefty2, (E-H,L) spaw and $(\mathrm{I}, \mathrm{J}, \mathrm{M})$ bmp 4 expressions in (A-J) 22-somite stage embryos. Normally, (A,E,I) left1+2, spaw and bmp 4 transcripts expressed in the left cardiac lateral plate mesoderm, $(\mathrm{B}, \mathrm{F}, \mathrm{J})$ have bilateral, $(\mathrm{C}, \mathrm{G})$ right and $(\mathrm{D}, \mathrm{H})$ absent expression in wtip morphants (1.035 pmol/embryo). Bar chart details the left-right patterning for control and wtip morphants. Wtip, Wilm's tumor 1 interacting protein; lefty1, left right determination factor 1; spaw, southpaw; bmp4, bone morphogenic factor 4; conMO, control morpholino oligonucleotide.

that mice lacking cardiac cilia developed abnormal ECCs and compact myocardium (CM) at e9.5 (39,76). Notably, our observations in zebrafish suggest that wtip knockdown embryos lack a differentiated AV boundary, which is similar to the findings in mice, which lack ECCs $(39,76)$. In addition, Wtip and cilia markers are co-expressed in the endocardium and myocardium prior to when the PE is formed in the zebrafish heart (data not shown), which may provide a connection to the AV valves that are simultaneously developing from the endocardium and myocardium. Previous studies have reported the timing and distribution of cilia in the embryonic mouse heart $(39,76)$. At e9.5, cilia on the endocardial cells are predominantly located on the luminal surface, while cilia in the mesenchymal cells of the developing cushions are randomly oriented. By e12.5, atrial and ventricular septation is underway; only few cilia are found on the atrial endocardial layer. In the ECCs, however, cilia are found on the endothelial surface and are visible in the mesenchymal cells. The present study is the first, to the best of our knowledge, to report cilia on PE cells. Cilia in the endothelium may sense the flow during embryonic heart development. PE cells may be sensing information about their environment that relates to pericardial fluid or heartbeats, or potentially PE cilia may be involved in sensing biochemical information, such as the movement of fluid.

In mice, cilia are required for cardiac development, independently from their function in the development of LR asymmetry $(39,76)$. Thus, it is possible that cardiac cilia function as mechanosensors, integrating information regarding flow, cardiac function and morphogenesis. If so, the prediction is that mutations in gene products that localize to cilia and/or basal bodies may affect heart morphogenesis and 
function. In zebrafish, many cystic mutant phenotypes accompany LR asymmetry defects originating in early somitogenesis stages, visible as altered spaw and left $1 / 2$ gene expression in the lateral plate mesoderm and by altered bmp 4 expression in the zebrafish heart.

In control embryos, the progression of cardiac looping is a morphogenic process. The cardiac looping angle is defined as the degree of difference in the anterior/posterior $(\mathrm{A} / \mathrm{P})$ body axis and the plane of the AV boundary (55). The present study was unable to detect alterations in the expression of early patterning and chamber identity genes, suggesting that additional causes must be responsible for the malformation in the heart. Of note, chamber-specific markers $a m h c$ and $v m h c$ were not altered, however, nрpa was detected throughout the heart, with no distinguishable exclusion from the AV boundary in wtip knockdown embryos. Cardiac morphogenesis was significantly morphologically and molecularly affected at 48 and 72 hpf in wtip knockdown embryos, and gene restriction at the AV boundary was lost.

A number of the cardiac morphology mutants described in the original zebrafish large-scale mutagenesis screens have been well characterized, and the mutated genes have been identified. However, whether any of these mutants exhibit defects in cardiac cilia formation or function remains unknown, since the presence of cilia in the heart was not formerly described. Cardiac cilia are beginning to be characterized in other animal model systems, including chickens (62) and mice (39). As it was unknown whether basal bodies could affect heart morphogenesis and function, it was unclear whether heart defects could also be associated with early embryonic defects, such as LR patterning, which are thought to involve ciliary function.

The zebrafish system offers unique advantages for studying cell biology during vertebrate organogenesis, as zebrafish embryos develop externally and are practically transparent throughout early development, thereby allowing non-invasive observation. Previous studies in zebrafish indicate that endocardial cells in the AV differentiate before the onset of epithelial-to-mesenchymal transformation, thereby defining a previously unappreciated step during AV valve formation $(80,81)$. New zebrafish mutants exhibiting AV valve development will provide a unique set of tools with which to further understand the genetic basis of PE cell behavior and its effect on heart development $(80,81)$. Importantly, AV-associated phenotypes have been observed in mutant mouse models (81). The combination of genetics and pharmacological studies in animal models and the cell biology should provide novel insights into the developmental biology of cardiac organogenesis and provide relevant information to predict and understand human valvular and septal malformations.

The current study provides the first genetic evidence, to the best of our knowledge, for a novel role for the Wtip basal body protein in regulating the PE cell fate during development. In addition, our tools for wtip knockdown will be valuable for future studies to determine how Wtip signaling, possibly mediated via cilia, could indirectly modulate cardiac looping or AV development. The present study may additionally provide an avenue for understanding how the PE stimulates a response to cardiac injury, leading to its eventual repair.

\section{Acknowledgements}

The authors would like to thank all members of the Obara laboratory for the helpful discussion, and Kathy Kyler and Hiroyuki Matsumoto for critical reading of the manuscript. The authors would like to acknowledge the Zebrafish Information Resource Center for providing fish. Professor Tomoko Obara acknowledges financial support from the University of Oklahoma Health Sciences Center (OUHSC). Professor Tomoko Obara was supported by NIH grants R21-DK069604 and R01-DK078209, and the Oklahoma Center for the Advancement of Science and Technology (OCAST) grant HR14-082. The present study is supported in part by the Diabetes Histology and Image Acquisition and Analysis Core Facility at OUHSC (NIH: COBRE-1P20RR024215).

\section{References}

1. DeHaan RL: Morphogenesis of the vertebrate heart. In: Organogenesis. DeHaan RL and Ursprung H (eds). Holt, Rinehart and Winston, New York, pp377-419, 1965.

2. Serbedzija GN, Chen JN and Fishman MC: Regulation in the heart field of zebrafish. Development 125: 1095-1101, 1998.

3. Bagatto B, Francl J, Liu B and Liu Q: Cadherin2 (N-cadherin) plays an essential role in zebrafish cardiovascular development. BMC Dev Biol 6: 23, 2006.

4. Fishman MC and Chien KR: Fashioning the vertebrate heart: Earliest embryonic decisions. Development 124: 2099-2117, 1997.

5. Mikawa T and Fishman DA: Retroviral analysis of cardiac morphogenesis: Discontinuous formation of coronary vessels. Proc Natl Acad Sci USA 89: 9504-9508, 1992.

6. Mikawa T and Gourdie RG: Pericardial mesoderm generates a populations of coronary smooth muscle cells migrating into the heart along with ingrowth of the epicardial organ. Dev Biol 174: 221-232, 1996.

7. Dettman RW, Denetclaw W Jr, Ordahl CP and Bristow J: Common epicardial origin of coronary vascular smooth muscle, perivascular fibroblasts, and intermyocardial fibroblasts in the avian heart. Dev Biol 193: 169-181, 1998.

8. Pérez-Pomares JM, Macías D, García-Garrido L and Munõz-Chápuli R: Immunolocalization of the vascular endothelial growth factor receptor-2 in the subepicardial mesenchyme of hamster embryos: Identification of the coronary vessel precursors. HIstochem J 30: 627-634, 1998.

9. Vrancken Peeters MP, Gittenberger-de Groot AC, Mentink MM and Poelmann RE: Smooth muscle cells and fibroblasts of the coronary arteries derive from epithelial-mesenchymal transformation of the epicardium. Anat Embryol (Berl) 199: 367-378, 1999.

10. Gittenberger-de Groot AC, Vrancken Petters MP, Bergweff M, Mentink MM and Poelmann RE: Epicardial outgrowth inhibition leads to compensatory mesothelial outflow tract collar and abnormal cardiac septation and coronary formation. Cir Res 87: 969-971, 2000.

11. Reese DE, Mikawa T and Bader DM: Development of the coronary vessel system. Circ Res 91: 761-768, 2002.

12. von Gise A and Pu WT: Endocardial and epicardial to mesenchymal transitions in heart development and disease. Circ Res 110: 1628-1645, 2012

13. Manner J: Experimental study on the formation of the epicardium in chick embryos. Anat Embryol (Berl) 187: 281-289, 1993.

14. Svensson EC: Deciphering the signals specifying the proepiardium. Cir Res 106: 1789-1790, 2010.

15. Bakkers J: Zebrafish as a model to study cardiac development and human cardiac disease. Cardiovasc Res 91: 279-288, 2011.

16. Kreidberg JA, Sariola H, Loring JM, Maeda M, Pelletier J, Housman D and Jaenisch R: WT-1 is reqiored for early kidney development. Cell 74: 679-691, 1993.

17. Kwee L, Baldwin HS, Shen HM, Stewart CL, Buck C, Buck CA and Laobow MA: Defective development of the embryonic and extraembryonic circulatory systems in vascular cell adhesion molecule (VCAM-1) deficient mice. Development 121: 489-503, 1995. 
18. Yang JT, Raybum H and Hynes RO: Cell adhesion events mediated by alpha 4 integrins are essential in placental and cardiac development. Development 121: 549-560, 1995.

19. Moore AW, Mclnnes L, Kreidberg J, Hastie ND and Schedl A YAC complementation shows a requirement for Wt1 in the development of epicardium, adrenal gland and throughout nephrogenesis. Development 126: 1845-1857, 1999.

20. Red-Horse K, Ueno H, Weissman IL and Krasnow MA: Coronary arteries from by developmental reprogramming of venous cells Nature 464: 549-553, 2010.

21. von Gise A, Zhou B, Honor LB, Ma Q, Petryk A and Pu WT: WT1 regulates epicardial epithelial to mesenchymal transition through $\beta$-catenin and retinoic acid signaling pathways. Dev Biol 356: 421-431, 2011.

22. Serluca FC: Development of the proepicardial organ in the zebrafish. Dev Biol 315: 18-27, 2008.

23. Liu J and Stainier DY: Tbx 5 and Bmp signaling are essential for proepicardium specification in zebrafish. Circ Res 106: 1818-1828, 2010.

24. Lepilina A, Coon AN, Kikuchi K, Holdway JE, Roberts RW, Burns CG and Poss KD: A dynamic epicardial injury response supports progenitor cell activity during zebrafish heart regeneration. Cell 127: 607-619, 2006.

25. Kikuchi K, Gupta V, Wang J, Holdway JE, Wills AA, Fang Y and Poss KD: tcf21+ epicardial cells adopt non-myocardial fates during zebrafish heart development and regeneration. Development 138: 2895-2902, 2011

26. Kikuchi K,Holdway JE, Major RJ,Blum N, Dahn RD, Begemann G and Poss KD: Retinoic acid production by endocardium and epicardium is an injury response essential for zebrafish heart regeneration. Dec Cell 20: 397-404, 2011.

27. Kim J, Wu Q, Zhang Y, Wiens KM, Huan Y, Rubin N, Shimada H Handin RI, Chao MY, Tuan TL, et al: PDGF signaling is required for epicardial function and blood vessel formation in regenerating zebrafish hearts. Proc Natl Acad Sci USA 107: 17206-17210, 2010

28. Wu H, Lee SH, Gao J, Liu X and Iruela-Arispe ML: Inactivation of erythropoietin leads to defects in cardiac morphogenesis. Development 126: 3597-3605, 1999.

29. Chen TH, Chang TC, Kang JO, Choudhary B, Makita T, Tran CM Burch JB, Eid H and Sucov HM: Epicardial induction of fetal cardiomyocyte proliferation via a retinoic acid-inducible trophic factor. Dev Biol 250: 198-207, 2002.

30. Sengbusch JK, He W, Pinco KA and Yang JT: Dual functions of [alpha]4[beta]1 integrin in epicardial development: Initial migration and long-term attachment. J Cell Biol 157: 873-882, 2002.

31. HatcherCJ,Diman NY,Kim MS,Pennisi D, Song Y, Goldstein MM Mikawa T and Basson CT: A role for Tbx5 in proepicardial cell migration during cardiogenesis. Physiol Genomics 18: 129-140, 2004.

32. Schlueter $\mathbf{J}$ and Brand T: A right-sided pathway involving FGF8/Snail controls asymmetric development of the proepicardium in the chick embryo. Proc Natl Acad Sci USA 106 7485-7490, 2009.

33. Schulte I, Schlueter J, Abu-Issa R, Brand T and Männer J: Morphological and molecular left-right asymmetries in the development of the proepicardium: A comparative analysis on mouse and chick embryos. Dev Dyn 236: 684-695, 2007.

34. Chen JN, van Eeden FJ, Warren KS, Chin A, Nüsslein-Volhard C, Haffter P and Fishman MC: Left-right pattern of cardiac BMP4 may drive asymmetry of the heart in zebrafish. Development 124 4373-4382, 1997.

35. Shu X, Huang J, Dong Y, Choi J, Langenbacher A and Chen JN: $\mathrm{Na}, \mathrm{K}-\mathrm{ATPase}$ alpha2 and Ncx4a regulate zebrafish left-right patterning. Development 134: 1921-1930, 2007.

36. Fakhro KA, Choi M, Ware SM, Belmont JW, Towbin JA, Lifton RP, Khokha MK and Brueckner M: Rare copy number variations in congenital heart disease patients identify unique genes in left-right patterning. Proc Natl Acad Sc USA 108: 2915-2920, 2011.

37. Chin AJ, Saint-Jeannet JP and Lo CW: How insights from cardiovascular developmental biology have impacted the care of infants and children with congenital heart disease. Mech Dev 129: 75-97, 2012.

38. Francis RJ, Christopher A, Devine WA, Ostrowski L and Lo C: Congenital heart disease and the specification of left-right asymmetry. Am J Physiol Heart Circ Physiol 302: H2102-H2111, 2012.

39. Slough J, Cooney L and Brueckner M: Monocilia in the embryonic mouse heart suggest a direct role for cilia in cardiac morphogenesis. Dev Dyn 237: 2304-2314, 2008.
40. Srichai MB, Konieczkowski M, Padiyar A, Konieczkowski DJ, Mukherjee A, Hayden PS, Kamat S, El-Meanawy MA, Khan S, Mundel P, et al: A WT1 co-regulator controls podocyte phenotype by shuttling between adhesion structures and nucleus. J Biol Chem 279: 14398-14408, 2004.

41. van Wijk NV, Witte F, Feike AC, Schambony A, Birchmeier W, Mundlos S and Stricker S: The LIM domain protein Wtip interacts with the receptor tyrosine kinase Ror2 and inhibits canonical Wnt signaling. Biochem Biophys Res Commun 390: 211-216, 2009.

42. Langer EM, Feng Y, Zhaoyuan H, Rauscher FJ III, Kroll KL and Longmore GD: Ajuba LIM proteins are snail/slug corepressors required for neural crest development in Xenopus. Dev Cell 14: 424-436, 2008.

43. Das Thakur M, Feng Y, Jagannathan R, Seppa MJ, Skeath JB and Longmore GD: Ajuba LIM proteins are negative regulators of the Hippo signaling pathway. Curr Biol 20: 657-662, 2010.

44. Bubenshchikova E, Ichimura K, Fukuyo Y, Powell R, Hsu C, Morrical SO, Sedor JR, Sakai T and Obara T: Wtip and Vangl2 are required for mitotic spindle orientation and cloaca morphogenesis. Biol Open 1: 588-596, 2012

45. Gana S, Veggiotti P, Sciacca G, Fedeli C, Bersano A, Micieli G, Maghnie M, Ciccone R, Rossi E, Plunkett K, et al: 19q13.11 cryptic deletion: Description of two new cases and indication for a role of WTIP haploinsufficiency in hypospadias. Eur J Hum Genet 20: 852-856,2012.

46. Westerfield M: The Zebrafish Book. A Guide For The Laboratory Use Of Zebrafish Danio (Brachydanio) Rerio. 4th edition. University of Oregon Press, Eugene, OR, 2000.

47. Feng J, Jia N, Han LN, Huang FS, Xie YF, Liu J and Tang JS: Microinjection of morphine into thalamic nucleus submedius depresses bee venom-induced inflammatory pain in the rat. J Pharm Pharmacol 60: 1355-1363, 2008.

48. Amack JD and Yost HJ: The T box transcription factor no tail in ciliated controls zebrafish left-right asymmetry. Curr Biol 14: 685-690, 2004

49. Hauptmann G and Gerster T: Multicolor whole-mount in situ hybridization. Methods Mol Biol 137: 139-148, 2000.

50. Thisse $\mathrm{C}$ and Thisse B: High-resolution in situ hybridization to whole-mount zebrafish embryos. Nat Protoc 3: 59-69, 2008.

51. Yelon D, Home SA and Stainier DY: Restricted expression of cardiac myosin genes reveals regulated aspects of heart tube assembly in zebrafish. Dev Biol 214: 23-37, 1999.

52. Berdougo E, Coleman H, Lee DH, Stainier DY and Yelon D: Mutation of weak atrium/atrial myosin heavy chain disrupts atrial function and influences ventricular morphogenesis in zebrafish. Development 130: 6121-6129, 2003.

53. Long S, Ahmad N and Rebagliati M: The zebrafish nodal-related gene southpaw is required for visceral and diencephalic left-right asymmetry. Development 130: 2303-2316, 2003.

54. Ahmad I, Pacheco M and Santos MA: Exzymatic and nonenzymatic antioxidants as an adaptaion to phagocyte-induced damage in Anguilla Anguilla L. following in situ harbor water exposure. Exotoxicol Environ Saf 57: 290-302, 2004.

55. Chernyavskaya Y, Ebert AM, Milligan E and Garrity DM: Voltage-gated calcium channel CACNB2 $(\beta 2.1)$ protein is required in the heart for control of cell proliferation and heart tube integrity. Dev Dyn 241: 648-662, 2012.

56. Kim S, Zaghloul NA, Bubenshchikova E, Oh EC, Rankin S, Katsanis N, Obara T and Tsiokas L: Nde1-mediated inhibition of ciliogenesis affects cell cycle re-entry. Nat Cell Biol 13: 351-360, 2011.

57. Pritchard-Jones K, Fleming S, Davison D, Bickmore W, Porteous D, Gosden C, Bard J, Buckler A, Pelletier J, Housman D, et al: The candidate Wilms' tumour gene is involved in genitourinary development. Nature 346: 194-197, 1990.

58. Armstrong JF, Pritchard-Jones K, Bickmore WA, Hastie ND and Bard JB: The expression of the Wilms' tumour gene, WT1, in the developing mammalian embryo. Mech Dev 40: 85-97, 1993.

59. Drummond IA, Majumdar A, Hentschel H, Elger M, Solnica-Krezel L, Schier AF, Neuhauss SC, Stemple DL, Zwartkruis F, Rangini Z, et al: Early development of the zebrafish pronephros and analysis of mutations affecting pronephric function. Development 125: 4655-4667, 1998

60. Carmona R, González-Iriarte M, Pérez-Pomares JM and Muñoz-Chápuli R: Localization of the Wilm's tumour protein WT1 in avian embryos. Cell Tissue Res 303: 173-186, 2001.

61. Ichimura K, Bubenshchikova E, Powell R, Fukuyo Y, Nakamura T, Tran U, Oda S, Tanaka M, Wessely O, Kurihara H, et al: A comparative analysis of glomerulus development in the pronephros of medaka and zebrafish. PLoS One 7: e45286, 2012. 
62. Van der Heiden K, Groenendijk BC, Hierck BP, Hogers B Koerten HK, Mommaas AM, Gittenberger-de Groot AC and Poelmann RE: Monocilia on chicken embryonic endocardium in low shear stress areas. Dev Dyn 235: 19-28, 2006.

63. Perner B, Englert C and Bollig F: The Wilms tumor genes wt1a and wt lb control different steps during formation of the zebrafish pronephros. Dev Biol 309: 87-96, 2007.

64. Auman HJ, Coleman H, Riley HE, Olale F, Tsai HJ and Yelon D: Functional modulation of cardiac form through regionally confined cell shape changes. PLoS Biol 5: e53, 2007.

65. Mably JD, Modhideen MA, Burns CG, Chen JN and Fishman MC: Heart of glass regulates the concentric growth of the heart in zebrafish. Curr Biol 13: 2138-2147, 2003.

66. Baker K, Warren KS, Yellen G and Fishman MC: Defective 'pacemaker' current (Ih) in a zebrafish mutant with a slow heart reate. Proc Natl Acad Sci USA 94: 4554-4559, 1997.

67. Jacob E, Drexel M, Schwerte T and Pelster B: Influence of hypoxia and of hypoxemia on the development of cardiac activity in zebrafish larvae. Am J Physiol Regul Integr Comp Physiol 283: R911-R917, 2002.

68. Vermot J, Forouhar AS, Liebling M, Wu D, Plummer D, Gharib M and Fraser SE: Reversing blood flows act through klf2a to ensure normal valvulogenesis in the developing heart. PLoS Biol 7: e1000246, 2009.

69. Nagai Y, Asaoka Y, Namae M, Saito K, Momose H, Mitani H, Furutani-Seiki M, Katada T and Nishina H: The LIM protein Ajuba is required for ciliogenesis and left-right axis determination in medaka. Biochem Biophys Res Commun 396: 887-893, 2010.

70. Witzel HR, Jungblut B, Choe CP, Crump JG, Braun T and Dobreva G: The LIM protein Ajuba restricts the second heart field progenitor pool by regulating Isl1 activity. Dev Cell 23: 58-57, 2012.

71. Essner JJ, Vogan KJ, Wagner MK, Tabin CJ, Yost HJ and Brueckner M: Conserved function for embryonic nodal cilia. Nature 418: 37-38, 2002.
72. Essner JJ, Amack JD, Nyholm MK, Harris EB and Yost HJ: Kupffer's vesicle is a ciliated organ of asymmetry in the zebrafish embryo that initiates left-right development of the brain, heart and gut. Development 132: 1247-1260, 2005.

73. Kramer-Zucker AG, Olale F, Haycraft CJ, Yoder BK, Schier AF and Drummond IA: Cilia-driven fluid flow in the zebrafish pronephros, brain and Kupffer's vesicle is required for normal organogenesis. Development 132: 1907-1921, 2005.

74. Wessely O and Obara T: Fish and frogs: Models for vertebrate cilia signaling. Front Biosci 13: 1866-1880, 2008.

75. Swanhart LM, Cosentino CC, Diep CQ, Davidson AJ, de Caestecker M and Hukriede NA: Zebrafish kidney development: basic science to translational research. Birth Defects Res C Embryo Today 93: 141-156, 2011

76. Brueckner M: Impact of genetic diagnosis on clinical management of patients with congenital heart disease: Cilia point the way. Circulation 125: 2178-2180, 2012.

77. Svensson LG: Percutaneous aortic valves: Effective in inoperable patients, what price in high-ris patients? J Thorac Cardiovasc Surg 140 (6 Suppl): S10-S13; discussion S86-S91, 2010.

78. Poss KD, Wilson LG and Keating MT: Heart regeneration in zebrafish. Science 298: 2188-2190, 2002.

79. Myklebust R, Engedal H, Saetersdai TS and Ulstein M: Primary $9+0$ cilia in the embryonic and the adult human heart. Anat Embryol (Berl) 151: 127-139, 1977.

80. Beis D, Bartman T, Jin SW, Scott IC, D'Amico LA, Ober EA, Verkade H, Frantsve J, Field HA, Wehman A, et al: Genetic and cellular analyses of zebrafish atrioventricular cushion and valve development. Development 132: 4193-4204, 2005.

81. Smith KA, Langendijk AK, Courtney AD, Chen H, Paterson D, Hogan BM, Wicking C and Bakkers J: Transmembrane protein 2 (Tmem 2$)$ is required to regionally restrict atrioventricular canal boundary and endocardial cushion development. Development 138: 4193-4198, 2011. 